\title{
Geschlecht als \\ Gabe und Aufgabe
} Intersexualität aus theologischer Perspektive

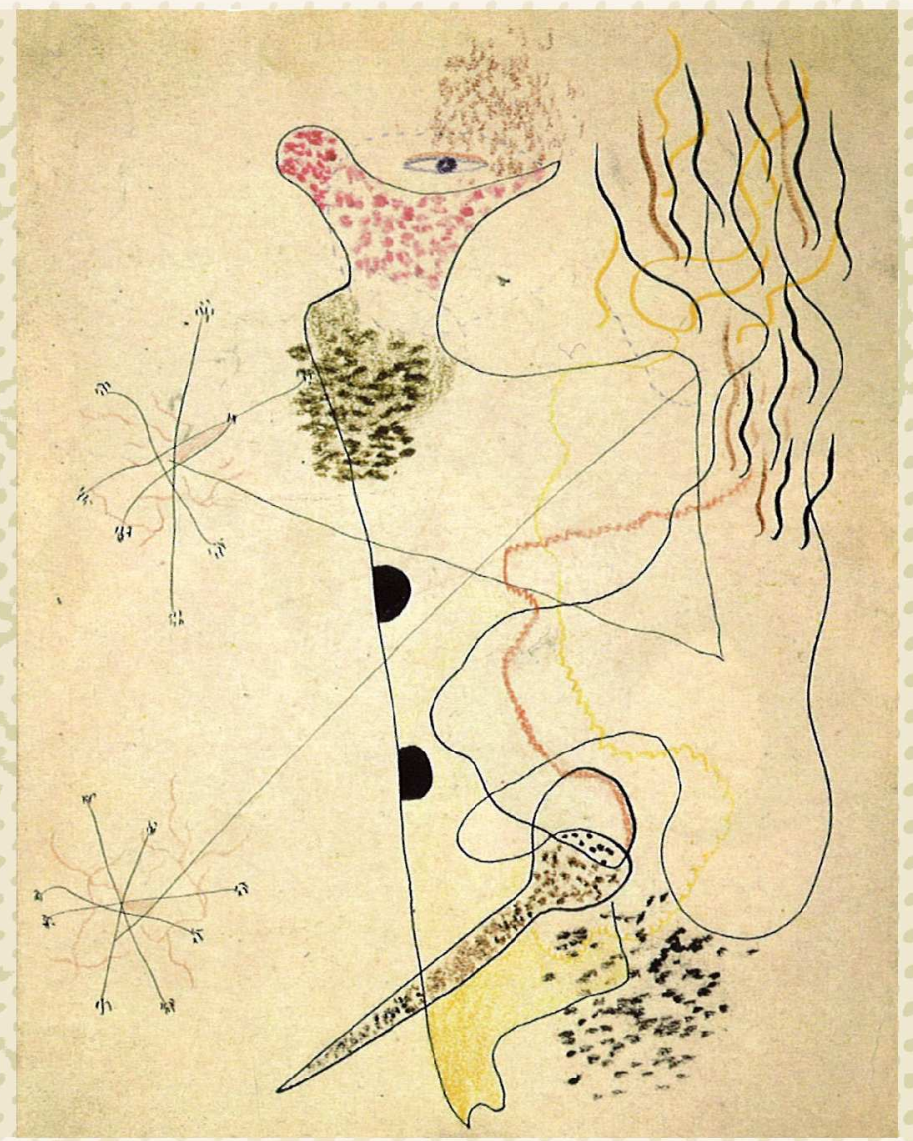


Conrad Krannich

Geschlecht als Gabe und Aufgabe 
$\mathrm{D}$ ie Reihe »Angewandte Sexualwissenschaft « sucht den Dialog: Sie ist interdisziplinär angelegt und zielt insbesondere auf die Verbindung von Theorie und Praxis. Vertreter_innen aus wissenschaftlichen Institutionen und aus Praxisprojekten wie Beratungsstellen und Selbstorganisationen kommen auf Augenhöhe miteinander ins Gespräch. Auf diese Weise sollen die bisher oft langwierigen Transferprozesse verringert werden, durch die praktische Erfahrungen erst spät in wissenschaftlichen Institutionen Eingang finden. Gleichzeitig kann die Wissenschaft so zur Fundierung und Kontextualisierung neuer Konzepte beitragen.

Der Reihe liegt ein positives Verständnis von Sexualität zugrunde. Der Fokus liegt auf der Frage, wie ein selbstbestimmter und wertschätzender Umgang mit Geschlecht und Sexualität in der Gesellschaft gefördert werden kann. Sexualität wird dabei in ihrer Eingebundenheit in gesellschaftliche Zusammenhänge betrachtet: In der modernen bürgerlichen Gesellschaft ist sie ein Lebensbereich, in dem sich Geschlechter-, Klassen- und rassistische Verhältnisse sowie weltanschauliche Vorgaben - oft konflikthaft - verschränken. Zugleich erfolgen hier Aushandlungen über die offene und Vielfalt akzeptierende Fortentwicklung der Gesellschaft.

\author{
BAND 4 \\ AngewANDTE SEXUALWISSENSCHAFT \\ Herausgegeben von Ulrike Busch, Harald Stumpe, \\ Heinz-Jürgen Voß und Konrad Weller, \\ Institut für Angewandte Sexualwissenschaft \\ an der Hochschule Merseburg
}




\author{
Conrad Krannich
}

\title{
Geschlecht als Gabe und Aufgabe
}

\author{
Intersexualität \\ aus theologischer Perspektive
}

Psychosozial-Verlag 
Die Open-Access-Publikation wurde durch eine Förderung des

Bundesministerium für Bildung und Forschung ermöglicht.

Dieses Werk ist lizenziert unter der Creative Commons Attribution-Non-

Commercial-NoDerivs 3.0 DE Lizenz (CC BY-NC-ND 3.0 DE).

Diese Lizenz erlaubt die private Nutzung und unveränderte Weitergabe, verbietet jedoch die Bearbeitung und kommerzielle Nutzung.

Weitere Informationen finden Sie unter: https://creativecommons.org/ licenses/by-nc-nd/3.0/de/

$$
\text { (c) } \underset{\mathrm{BY}}{\mathrm{BY}}\left(\mathrm{ND}_{\mathrm{ND}}\right.
$$

Bibliografische Information der Deutschen Nationalbibliothek Die Deutsche Nationalbibliothek verzeichnet diese Publikation in der Deutschen Nationalbibliografie; detaillierte bibliografische

Daten sind im Internet über http://dnb.d-nb.de abrufbar.

\author{
Originalausgabe \\ C 2016 Psychosozial-Verlag, Gießen \\ E-Mail: info@psychosozial-verlag.de \\ www.psychosozial-verlag.de
}

Alle Rechte vorbehalten. Kein Teil des Werkes darf in irgendeiner Form (durch Fotografie, Mikrofilm oder andere Verfahren) ohne schriftliche

Genehmigung des Verlages reproduziert oder unter Verwendung

elektronischer Systeme verarbeitet, vervielfältigt oder verbreitet werden.

Umschlagabbildung: Federico García Lorca, »Pierrotpriápico«, um 1932-1936

Umschlaggestaltung und Innenlayout nach Entwürfen von Hanspeter Ludwig, Wetzlar

www.imaginary-world.de

Satz: metiTEC-Software, me-ti GmbH, Berlin

ISBN 978-3-8379-2544-9 (Print)

ISBN 978-3-8379-6800-2 (E-Book-PDF)

ISSN 2367-2420 (Print)

https://doi.org/10.30820/9783837968002 


\section{Inhalt}

1. Einleitung 7

1.1 Ein Intersex berichtet 7

1.2 Relevanz 9

1.3 Anliegen des Buches und analytisch-

2. Das vieldeutige biologische Geschlecht 13

2.1 Biologisches Geschlecht und die Frage nach Eindeutigkeit

2.2 Geschlecht zwischen Konstruktivismus und Realismus $\quad 22$

2.3 Zwischenfazit 28

3. Intersex in theologischer Perspektive 31

3.1 Geschlechtliche Nichteindeutigkeit und das leibliche Selbsterleben

3.2 Eindeutigkeit zwischen geordneter und zu ordnender Schöpfung 43

3.3 Geschlechtliche Nichteindeutigkeit und Zwang zur Eindeutigkeit 
4. Intersexualität als theologische Herausforderung

5. Ausblick

Literatur 


\section{Einleitung}

\subsection{Ein Intersex' ${ }^{1}$ berichtet}

»Ende 1972 wurde ich wegen ausbleibender Menstruation humangenetisch untersucht, es wurde eine XY-Gonadendysgenesie/Hermaphroditismus masculinus [>weibliches < Erscheinungsbild bei XY-Geschlechtschromosomenpaar] festgestellt. [...] Im März 1973 [...] wurden beide Keimdrüsen [d.h. die Hoden] komplett entfernt. [...] Man erklärte mir, dass ich nun Hormontabletten lebenslang einnehmen müsse. Meine schulischen Leistungen wurden schlechter und ich verließ das Gymnasium. In der Folge befolgte ich jeden ärztlichen Rat. Jedoch musste ich alle paar Jahre die Östrogenpräparate wechseln, da sich mein Gesundheitszustand kontinuierlich verschlechterte. [...] Ich dachte, an den Hormonen kann es nicht liegen, weil mir die behandelnden Ärzte zusicherten, mit den Hormonen sei alles in Ordnung. [...] Obwohl sich mein körperlicher Zustand, mein Wohlbefinden, meine Teilhabe am gesellschaftlichen und kulturellen Leben immer weiter verschlechterte[n], teilte mir die Psycho-

1 Hermaphroditismus ist der klassische und lange Zeit verbreitete Begriff zur Bezeichnung geschlechtlicher Nichteindeutigkeit. Obwohl Hermaphroditismus sowohl Menschen mit Merkmalen beider Geschlechter als auch Menschen mit nicht-typischen Geschlechtsmerkmalen bezeichnet, gilt diese Definition noch immer als angemessen. Der Begriff Zwitter wird zum Teil als Selbstbezeichnung gewählt, ist aber aufgrund seiner negativen Konnotation zur Fremdbezeichnung unangemessen. Der Begriff Intersexualität wurde Anfang 
login mit: >Sie haben viele gesunde Anteile, [S]ie sind eine ganz normale Frau. $<$ Dies war mir keine Hilfe. [...] Nachdem mir [nach jahrelanger Recherche und Rekonstruktion der >Krankengeschichte $<$ bewusst wurde, dass ich kerngeschlechtlich eher keine Frau bin, [und] ich erkannte, dass die an mir vollzogene Kastration meiner Hoden der Grund meines gesundheitlichen und de $[s]$ damit einhergehende[n] Leistungseinbruch [s war und] die gegengeschlechtliche Hormontherapie mich 32 Jahre von einem erfüllten Leben entfernt ha[t], stellte ich meine Hormonversorgung mit ärztlicher Begleitung auf Testosteron um. [...] Die Folgen der Östrogentherapie zwischen 1973-2005 [...] waren Arbeitsplatzwechsel incl. Arbeitslosigkeit sowie mehrere Umzüge und Ende von Beziehungen[. Sie] sind einzig durch die ablative Kastration und d[ie] Östrogene sowie $\mathrm{d}[\mathrm{ie}]$ falschen gesellschaftlichen, rechtlichen, psychologischen und medizinischen Vorstellungen von $>$ den beiden richtigen Geschlechtern < verursacht - lagen also zu keinem Zeitpunkt in meiner eigenen Person. [...] Weitere Absurditäten und Aspekte meine Lebens sind: Eine gesetzliche Vorschrift koppelt das Krankenkassenkarte[n]Geschlecht an den Personenstand. Eine > männliche< Krankenkassenkarte wird mir ohne Personenstand[s]änderung verweigert. So kommt es wegen >meiner weiblichen Karte< vor, dass zu festgestellten Laborwerten nicht die männlichen, sondern - weil automatisiert - die weiblichen Referenzwerte aufgeführt werden. Dies führt zu Fehldiagnosen und Falschbehandlungen. Es wäre zwar einfach für mich, den Personenstand $[. .$.$] zu ändern - ich bin jedoch mit einem [e]chten$

des 20. Jahrhundert von dem Arzt Richard Goldschmidt geprägt und bezeichnete die geschlechtlichen Zwischenstufen zwischen den eindeutigen Merkmalen männlicher oder weiblicher Geschlechtlichkeit. Nicht nur wegen der mitklingenden polar-dichotomen Geschlechterkonfiguration erscheint der Begriff problematisch. Der Ausdruck Intersexualität führt auch immer wieder zu dem Missverständnis, dass von sexueller Orientierung die Rede sei. Als mindestens genauso problematisch erweist sich der medizinische Terminus Disorders of sex development (DSD), in dem die Pathologisierung von geschlechtlicher Devianz schon begrifflich vollzogen ist. Die Intersex-Verbände plädieren für den Begriff Intersex bzw. Intergeschlechtlichkeit. Die Schwierigkeiten, die sich mit dem Präfix »inter-« verbinden, sind damit nicht behoben. Diese hat der Autor im Blick und folgt somit dem Vorschlag der Selbstorganisationen. Einen Überblick über die Begriffe, ihre Geschichte und Verwendung bietet Voß (2012, S. 9-12). 
Hermaphroditen mit männlichem Personenstand verheiratet [...]. Unsere Ehe könnte also gefährdet sein. [...] (Intersexuelle Menschen e.V., 2011, S. 46-49).

\subsection{Relevanz}

Die geschilderte Entfernung der Keimdrüsen und die anschließende hormonelle Behandlung fußen auf der medizinischen Indikation geschlechtlicher Nichteindeutigkeit. Der Entwicklung des_r Betroffenen in seiner_ihrer körperlichen Verfasstheit ihren Lauf zu lassen, wäre die in ihren Folgen harmloseste Möglichkeit des medizinischen Umgangs mit diesem »Fall « geschlechtlicher »Nichteindeutigkeit « gewesen. Die Norm, ein Intersex-Kind einem der beiden vorgegebenen Idealgeschlechter anzugleichen, zerstörte dagegen ein Leben in seinen Entfaltungsmöglichkeiten. Es wird deutlich: Das Alltagsverständnis der Mehrheitsgesellschaft von Geschlechtlichkeit erweist sich angesichts solcher Leiderfahrungen als korrekturbedürftig.

Die binäre Geschlechterkonfiguration ist eine Elementarkategorie menschlicher Selbst- und Weltwahrnehmung und als solche tief in das Alltagsbewusstsein eingebrannt, was nicht zuletzt im Personenstandsrecht und den davon betroffenen alltäglichen (Rechts-)Dingen (z. B. Fragebögen, Geburtsangaben, öffentlichen Toiletten) symptomatisch zutage tritt. Sie stellt eine leistungsfähige, aber angesichts der geschlechtlichen Vielgestaltigkeit unzulässige Vereinfachung dar. So sind die Konstrukthaftigkeit der dichotomen Idealgeschlechter, ihre Konstruktionsmechanismen sowie die sie verschleiernden Naturalisierungsversuche nicht erst seit dem Beginn feministischer Forschung im frühen 20. Jahrhundert in der Kritik. ${ }^{2}$ Der Weg von der theoretischen Reflexion hinein ins allgemeine Bewusstsein ist indes lang. So wird ein bestimmtes Verständnis von Geschlecht als vermeintlich natürlich - und damit unbestreitbar - immer wieder argumentativ für unterschiedliche politische, ethisch-normative Programme in Anspruch genommen.

2 Vgl. dazu z.B. die Untersuchungen zur Entwicklung der Geschlechtertheorien von Laqueur (1992), Honegger (1991), Voß (2010). 
Im Umgang mit Intersex stehen die Kirchen dem Rest der Gesellschaft in nichts nach. In kirchlichen Stellungnahmen wird das Thema Intersex konsequent ausgeblendet. ${ }^{3}$

Die Beschäftigung mit Intersex darf sich nicht in der Auseinandersetzung mit bestimmten Geschlechterkonfigurationen erschöpfen oder gar dafür instrumentalisiert werden. Wichtiger ist es, IntersexNarrative in die Mehrheitsgesellschaft zu tragen. Beide Anliegen, die kritische Arbeit an der Geschlechterordnung und die Popularisierung von Intersex-Lebensgeschichten, können meines Erachtens nicht gegeneinander ausgespielt werden, sondern müssen zusammen verfolgt werden. Das größte Hindernis für die gleichberechtigte gesellschaftliche Teilhabe stellt für Intersexe nach wie vor die Mehrheitsannahme einer exklusiv binär-geschlechtlichen Grundkonfiguration des Menschen dar, weshalb die theoretische Arbeit am Geschlechterverständnis noch nicht getan ist. Die Kritik am Geschlecht als Ordnungskategorie gewinnt/erhält erst im Gespräch mit Intersexen, ihren Biografien und ihren unterschiedlichen Meinungen zu Zweigeschlechtlichkeit Relevanz und Differenziertheit.

\subsection{Anliegen des Buches und analytisch- argumentatives Vorgehen}

Die Anfragen an ein eng geführtes Verständnis menschlicher Geschlechtlichkeit bilden also den Ausgangspunkt dieses Buches. Sie wendet sich gegen die nicht hinterfragte theologische Inanspruchnahme einer vermeintlich natürlichen zweigeschlechtlichen Grundkonfiguration des Menschen, nach der alles, was nicht als passend in diesen Rahmen eingeordnet werden kann, nicht mehr anerkannt wird. Die theologische Herausforderung in der Auseinandersetzung mit Intersex geht über die Kritik an einer normativen Zweigeschlechtlichkeit hinaus. (www.ead.de), insbes. deren Arbeitskreis »Kinder in Kirche und Gesellschaft«. 
Die bereits im Titel des Buches implizierte Fragestellung zerfällt in zwei unterscheidbare Teilfragen, die im Verlauf dieser Arbeit immer wieder ineinandergreifen und miteinander verhandelt werden: Inwiefern stellt Intersex eine Herausforderung dar? Was ist daran von theologischem Interesse? Der zweite Teil des Buches entwickelt also eine theologische Perspektive auf das im ersten Teil freigelegte Phänomen nicht typischer Geschlechtlichkeit.

Die gemeine Lesart ist nicht nur verantwortlich für zerstörte Lebensmöglichkeiten. In der biologisch-medizinischen Forschung zur Geschlechtsdetermination erweist sie sich als Fehlkonzeptionalisierung. Ich stütze mich in dieser These im Wesentlichen auf die Arbeiten des Biologen und Medizinethikers Heinz-Jürgen Voß. Dieser hinterfragt nicht nur die neueste biologisch-medizinische Geschlechterforschung, sondern überblickt kritisch die Prozesse und Theoriestränge, die in Naturphilosophie und Medizin zu einer Engführung in der Wahrnehmung von Geschlecht und auf die Wahrnehmung von Geschlecht als Erklärungs- und Ordnungskategorie geführt haben.

Ein zur binären Geschlechtseinteilung alternatives - und angesichts der faktischen Vielgestaltigkeit und Vieldeutigkeit plausibleres - Verständnis von Geschlecht bietet im Anschluss der konstruktivistische Theoriestrang feministischer Forschung nach Judith Butler. Ihre Gedanken zu Geschlecht und Geschlechterordnung sind die zweite außertheologische Bezugsgröße, auf die ich zurückgreife. Butler zeigt, in welchem Maße die geschlechtliche Nichteindeutigkeit eine gemachte Nichteindeutigkeit ist, die auf sozialen Konstruktionsmechanismen und auf der Setzung von Eindeutigkeit und Nichteindeutigkeit beruht und nicht auf einer natürlichen Andersartigkeit. Gerade die biologisch-medizinische Auseinandersetzung mit Geschlecht offenbart, dass auch das Geschlecht der nicht-pathologisierten Mehrheit sehr viel fraglicher und vielgestaltiger ist, als gemeinhin angenommen. Die konstitutive (geschlechtliche) Vielgestaltigkeit und Nichteindeutigkeit eines jeden Menschen wird mit der Konstruktion einer Gruppe geschlechtlich nichteindeutiger Menschen (Intersexe) in einen klar abgegrenzten Bereich gebannt.

Der dieser Ausgrenzungspraxis vorausgehende, problematische Umgang mit der eigenen und fremden (geschlechtlichen) Vieldeutigkeit und Vielgestaltigkeit ist der Aspekt der Beschäftigung mit Intersex, der die- 
sem Buch als theologischer Anknüpfungspunkt dient: Im Umgang mit Intersex im Rahmen geschlechtlicher Kategorisierungsversuche zeigt sich symptomatisch auch der Umgang mit der eigenen, leiblich erfahrenen und sozial domestizierten Nichteindeutigkeit und Vieldeutigkeit.

Dass der Weg beschritten wird von der Vielgestaltigkeit von Geschlecht als außertheologischem Phänomen hin zu der Frage, ob und auf welche Weise es sich hier um ein theologisches Problem handelt, verweist auf den primären Wabrnehmungskontext. Damit ist nicht gesagt, dass Anfragen an die Fixierung auf binär codierte Modelle von Geschlechtlichkeit und Geschlecht als Ordnungskategorie überhaupt nicht auch aus der theologischen Explikation des christlichen Glaubens heraus erwachsen können. Gleichermaßen als Reaktion auf die außertheologischen Erkenntnisse zu menschlicher Geschlechtlichkeit wie auch als Ergebnis theologischen Nachdenkens über den Umgang mit geschlechtlicher Nichteindeutigkeit soll deshalb »der theologische Ort der Rede « von Geschlecht genauer untersucht und konturiert werden. Ein flexiblerer Umgang mit Geschlechterkategorien ist möglich.

Die Beschäftigung mit Intersex soll nicht auf die Zuwendung zu einer marginalisierten Gruppe beschränkt werden, die in den kirchlichkaritativen Lebensäußerungen noch nicht angemessenen berücksichtigt wird; Intersex verweist vielmehr auf eine grundsätzlich hinterfragbare, vereinfachende Wirklichkeitssicht, die auch in vielen theologischen Systemen noch immer als selbstevident in Anspruch genommen wird. Der Aufbau dieses Buches erwächst aus dem Versuch, ein nicht-genuin theologisches Phänomen theologisch zur Sprache zu bringen. Das eklektische Vorgehen ist dem Zugang der Arbeit geschuldet. In der Interpretation der außertheologischen Erkenntnisse mithilfe einzelner protestantisch-theologischer Lehrstücke berufe ich mich nicht auf eine einzelne Lehrmeinung, auch weil Intersex als eigene theologischanthropologische Herausforderung bislang kaum thematisiert worden ist. Ich hoffe, dass gerade in der Übersicht verschiedener theologischer Entwürfe unterschiedliche Aspekte des Problems nachvollziehbar zum Ausdruck kommen. 


\section{Das vieldeutige biologische Geschlecht}

\subsection{Biologisches Geschlecht und die Frage nach Eindeutigkeit}

\section{Zum verbreiteten, aber verkürzten Verständnis von Geschlecht}

Beim biologischen Geschlecht wird gewöhnlich mindestens zwischen chromosomalem, gonadalem, hormonalem (endokrinem) und äußerlichem Geschlecht unterschieden. Die geschlechtsdeterminierenden Vorgänge bei der Fortpflanzung finden primär auf chromosomaler Ebene statt. Je nachdem, welche Chromosomen der elterlichen Keimzellen in den Teilungsvorgängen der Fortpflanzung zusammenkommen, erhält das entstehende Lebewesen neben 22 strukturell gleichen Chromosomenpaaren auch zwei X- (XX, weiblich) oder ein X- und ein Y-Chromosom (XY, männlich). Neben dem Chromosomensatz kann Geschlechtlichkeit auch mittels der Keimdrüsen (Gonaden), also anhand vorhandener Hoden oder Eierstöcke bestimmt werden. Maßgeblich an der Gonadenentwicklung beteiligt ist vermutlich das sogenannte SRY-Gen auf dem Y-Chromosom, das für die Ausbildung der Hoden entscheidend zu sein scheint und zu einer männlichen Entwicklung der inneren Geschlechtsorgane führt - entsprechend erfolgt bei Abwesenheit oder Nichtfunktionieren des SRY-Gens eine weichliche Entwicklung der Geschlechtsanlage.

Im (medizinischen) Alltag wird das Geschlecht allerdings in der Regel aufgrund der äußeren Geschlechtsorgane bestimmt. Auch diese 
entwickeln sich aus einer gemeinsamen Anlage in der späten Embryonalphase in Richtung männlich (u. a. Penis, Hodensack) oder weiblich (u.a. Klitoris, Schamlippen). Die Differenzierung der Organanlage wird unter anderem von Sexualhormonen gesteuert, deren Bildung man dem Zwischenhirn (Hypothalamus) und der Hirnanhangsdrüse (Hypophyse) zuschreibt, welche auch für die Steuerung anderer Hormone verantwortlich sind. Obwohl in unterschiedlicher und für das »jeweilige Geschlecht « spezifischer Konzentration kommen die sogenannten Sexualhormone (z. B. Testosteron, Östradiol, Estron u. a.) bei »beiden Geschlechtern « vor. Sie sind also nicht geschlechtsspezifisch und werden nicht nur in den Keimdrüsen gebildet.

\section{Die Pathologisierung geschlechtlicher Nichteindeutigkeit}

Bei den genannten Parametern zur Bestimmung des biologischen Geschlechts können Abweichungen von der durchschnittlichen Ausprägung auftreten. Ausgehend von einem Modell, das Geschlecht als bipolar versteht, werden Devianzen als intersexuell, d.h. als pathologische Ausprägung zwischen den eindeutigen Polen männlicher und weiblicher Geschlechtlichkeit verstanden. Der von Richard Goldschmidt 1915 geprägte Begriff Intersexualität bezeichnet sehr unterschiedliche Phänomene, deren Gemeinsamkeit es ist, dass sie in dem gängigen zweigeschlechtlichen Kategorien-Rahmen nicht ohne Weiteres darstellbar sind. Das sind neben nicht »typischen « äußerlichen Geschlechtsmerkmalen z. B.:

$>$ Eine abweichende Keimdrüsenanlage: Wenn sowohl parige Eierstöcke als auch paarige Hoden in einem Individuum angelegt sind, wird von echtem Hermaphroditismus gesprochen, bei teilweiser Anlage von Pseudo-Hermaphroditismus.

$>$ Abweichende Anzabl der Geschlechtschromosomen: Zu nennen sind z. B. das Klinefelter-Syndrom (47, XXY), das Turner-Syndrom (45, X0 d. h. nur ein X-Chromosom) oder sogenannte YPolysomien (47, XYY; 48, XXYY; 48, XYYY; 49, XYYYY). Die Varianzen der Geschlechtschromosomen können sich auch phänotypisch in einer vom Durchschnitt abweichenden Ausbildung der (Sexual-)Organe äußern. Wenn das chromosoma- 
le Geschlecht, z. B. als Folge abweichender embryonaler Teilungsvorgänge, nicht für alle Zellen oder Gewebe identisch ist, spricht die Medizin von einem sogenannten chromosomalen Mosaik. Neben der Chromosomenzahl kann auch die Struktur der Chromosomen selbst Unterschiede aufweisen (z. B. durch Mutation).

$>$ Ein von der Geschlechternorm abweichender Hormonhaushalt.

Nicht alle Varianzen schlagen sich im Erscheinungsbild nieder. Und längst nicht alle Formen von »Intersex « gehen mit körperlichen Einschränkungen bzw. Minderungen der Lebensqualität einher. Die Schätzungen des Bevölkerungsanteils der Menschen, die in mindestens einer der genannten Hinsichten keinem der typischen Geschlechter entsprechen, gehen weit auseinander. Verantwortlich dafür ist auch, dass in der deutschen Klassifikation Varianzen wie das Klinefelter- und das Turner-Syndrom nicht zu »Intersexualität « (bzw. zu disorders of sex development [DSD]) gezählt werden. International hingegen hat man sich darauf verständigt, sie einzubeziehen.

Geprägt von der Einsicht, welch hohen Stellenwert Sozialisierung, Erziehung und Erfahrung schon auf die frühkindliche Entwicklung haben, mahnt das derzeitig vorherrschende sogenannte frühe Behandlungsparadigma zu einem schnellen, geburtsnahen Eingriff im Fall von geschlechtlicher Nichteindeutigkeit. Nur so sei ein gesundes Hineinwachsen in die zugewiesene Geschlechterrolle - männlich oder weiblich - gewährleistet. Voß (2012, S. 13) verweist darauf, dass die Vermeidung von homosexuellem Verhalten ein wesentliches Argument für die Praxis der Geschlechtszuweisung und »-vereindeutigung « war. Aussehen und heterosexuelle Funktionstüchtigkeit der Genitalien (Penetrationsfähigkeit gegenüber Penetrierbarkeit, Urinierfunktion etc.) sind maßgeblich (Voß, 2010, S. 223). Diesem auch als Optimal Gender Policy bezeichneten Behandlungsprogramm liegt die Vorstellung zugrunde, dass es sich bei jeder Art von geschlechtlicher »Uneindeutigkeit « um einen pathologischen Befund handele, der - auch nach Machbarkeitserwägungen - gegebenenfalls operativ, also maximalinvasiv zu korrigieren und durch $\gg$ Hormontherapien « im weiteren Lebensverlauf zu begleiten sei (ebd., S. 218-227). Gemessen am »Behandlungserfolg « scheint das Festhalten am »me- 
dizinischen Imperativ « (Grosz, 1996, S. 64) der frühen Operation allerdings unhaltbar. ${ }^{4}$

Ein Umdenken beim medizinischen Umgang mit Intersex ist insofern zu verzeichnen, als dass sich neben der allgemeinen Stärkung des Mitspracherechts von Patient_innen (bzw. ihrer Vertreter_innen) nach und nach auch das Ideal des_r umfassend aufgeklärten, nicht nur zustimmungsfähigen, sondern selbstbestimmten Patienten_in durchsetzt (Full consent policy) (Voß, 2010, S. 225). Allerdings fehlt es nach wie vor an verbindlichen Prinzipienkatalogen und einer rechtlich wirksamen Verankerung des Selbstbestimmungsrechts des_r Intersex, um etwaige, das Geschlecht typisierende, Operationen nur selbstbestimmt und $\mathrm{ab}$ einem einwilligungsfähigen Alter durchzuführen. Auch die Unterscheidung zwischen »geschlechtsvereindeutigenden « und »geschlechtszuordnenden « medizinischen Maßnahmen und ein damit einhergehender vermeintlich behutsamerer Umgang mit dem Phänomen kann noch nicht als medizinischer Standard bezeichnet werden (Deutscher Ethikrat, 2012, S. 27f.).

\section{Veränderungen in den Geschlechtertheorien}

Die Fixierung auf das » natürliche « Substrat von Geschlecht einerseits und das neuzeitliche Verständnis von geschlechtlicher Normalität und Eindeutigkeit andererseits sind nicht so selbstevident wie gemeinhin angenommen. Voß’ Untersuchung naturphilosophischer und biologischmedizinischer Geschlechtermodelle von 2010 zeigt, dass die Auswahl der für die Geschlechtsbestimmung in Betracht gezogenen Merkmale schon immer umstritten war und entscheidend von den allgemeinen gesellschaftlichen und wissenschaftlichen Entwicklungen und den technischen Möglichkeiten abhing (Voß, 2010, S. 233). Voß kritisiert damit die verhältnismäßig statische chronologische Einteilung Thomas Laqueurs (1992). Dieser unterscheidet zwischen modernen Zweigeschlechtermodellen (die von einem geschlechtsspezifischen Prinzip bzw. einer für

4 Für einen Überblick und eine kritische Sichtung der Ergebnisse neuerer Outcome-Studien zum sogenannten Behandlungserfolg von geschlechtszuweisenden und -vereindeutigenden Eingriffen vgl. Voß (2012, S. 50-65). 
Männer und Frauen getrennten Geschlechtsanlage ausgehen) und vormodernen, entwicklungszentrierten Eingeschlechtermodellen (die Geschlechterunterschiede lediglich als Perfektionsgrade begreifen und vor allem auf soziale Unterschiede der Geschlechter abheben). Laqueur übersieht nach Voß (2010), dass zu allen Zeiten divergierende Modelle von Zeugung und geschlechtlicher Differenzierung miteinander konkurrierten und dass aus beiden Modelltypen argumentativ sowohl Geschlechtergleichheit als auch Geschlechterdifferenz abgeleitet werden konnte.

Gleiches gilt für die Deutungsmöglichkeiten der theoretischen Grundannahmen. So war es im 17. und 18. Jahrhundert aufgrund der postulierten Trennung von Körper und Geist möglich, trotz angenommener physiologischer Unterschiede die Gleichstellung von Mann und Frau zu fordern (ebd., S. 113f.). Einzelne Wissenschaftler_innen leiteten aus der körperlichen Beschaffenheit der Frau gar ihre Höherentwicklung ab und kehrten damit die hierarchisierenden Reduktionsmodelle um, die auf ähnlichen Vorannahmen beruhten (ebd., S. 114). Zudem bezogen sich die Theorien in ihrer Bestimmung von Geschlecht nicht immer auf die äußere Erscheinung oder den jeweiligen reproduktiven Beitrag, sondern fokussierten mitunter psychisch-seelische Grundlagen (ebd., S. 116, S. 233).

Mit der Einführung des Entwicklungsgedankens bestimmte in den Jahrzehnten nach der Französischen Revolution zunächst die Betonung der Gleichheit der Geschlechter das Diskussionsfeld. In diesem Theorierahmen betrachtet der Mediziner Ignaz Döllinger auch Hermaphroditismus als mögliches (gesundes) Geschlecht:

»[W]ie der Embryo nur Mensch, nicht Weib und nicht Mann seyn kann, so haben auch seine keimenden Genitalien keinen Geschlechtscharakter. Im Hermaphroditen [Hervorheb. d. Verf.] ist diese Differenz fixiert. Die menschlichen Geschlechtsteile sind nicht absolut männlich, sondern männlichweiblich, und nicht weiblich, sondern weiblichmännlich, daher die Harmonie ihres Baues, und die Möglichkeit einer Uebergangsbildung [...] « (Döllinger, 1816, S. 390; zit. n. Voß, 2011, S. 86f.). ${ }^{5}$

5 Für weitere Vertreter_innen für den Gleichheitsgedanken in naturphilosophischen und medizinischen Abhandlungen zum Geschlecht seit der Aufklärung vgl. Voß (2010, S. 120-187; 2011, S. 85-98). 
Auch dort, wo an dem Gedanken einer grundlegenden Differenz zwischen Mann und Frau festgehalten wurde, bestanden hinsichtlich ihrer Verortung und ihres Stellenwerts erhebliche Unterschiede. Die umfassende Naturalisierung von Geschlechtlichkeit und geschlechtlicher Differenz ist also keinesfalls der zeitlose Konsens eines fortschreitenden Forschungsprozesses. Sie spiegelt - wo sie gedacht wird - vielmehr den gegenwärtigen Bestand an gesellschaftlich-kulturell-geistigen Bedingungen für die Bestimmung von Geschlechtlichkeit wider (Voß, 2010, S. 89-236).

Ein Beispiel nicht nur für den gesellschaftlichen Einfluss auf wissenschaftliche Theoriebildung, sondern auch dafür, wie massiv wissenschaftliche Forschung durch die Gesellschaft ermöglicht oder verhindert wird, zeigt die ideologische Säuberung der deutschen Universitäten durch die Nationalsozialisten. Mit der Verfolgung Richard Goldschmidts und der Ermordung ihm fachlich nahestehender Kollegen bricht ein Theoriezweig innerhalb der Hormonforschung ab, dessen Komplexität erst im fortgeschrittenen 20. Jahrhundert wieder eingeholt werden sollte (Voß, 2011, S. 144f.).

Dank der Entwicklung immer sensiblerer Untersuchungsmethoden verlagerte sich die Suche nach den an der Geschlechtsdetermination beteiligten Faktoren immer mehr in den molekularen Mikrokosmos (Voß, 2010, S. 17; Schochow, 2010). Dass bei der Verschiebung des Gegenstandsbereichs in die nur noch einer Fachminderheit zugänglichen Bereiche die dichotome Geschlechtervorstellung neue Beachtung gewann, wird am ehesten aus der einfachen Operationalisierbarkeit des binären Geschlechterverständnisses und den Geschlechter-Konventionen der wissenschaftstreibenden Schichten verständlich. ${ }^{6}$

Mit der Suche nach und der vermeintlichen Feststellbarkeit von geschlechtlicher Eindeutigkeit auf immer grundlegenderer, mikroskopischer Ebene wurde das Geschlecht einer immer größeren Anzahl von

6 Ferruta (2010, S. 37-64) verweist im Zusammenhang mit dieser Frage auf die Sakralisierung des Weiblichen und Privaten im Bürgertum des ausgehenden 18. Jahrhunderts. Interessant ist auch ihr Hinweis auf Pathos und Herrschaftsanspruch der naturwissenschaftlichen Aufbrüche dieser Zeit. Zur gesellschaftlichen Eingebundenheit der medizinischen Geschlechterforschung vgl. Lorber (1999, S. 85-106). Das Kapitel ist treffend überschrieben: »Man sieht nur, was man glaubt«. Vgl. auch Voß (2012, S. 22-28). 
Menschen fraglich. Die Entdeckung von rein äußerlich nicht wahrnehmbaren Devianzen und die »Übertragung der aus dem Körperinneren gewonnenen Diagnose auf die zu lebende Geschlechterrolle « (Voß, 2010, S. 217) hatten enorme soziale Auswirkungen. Die neuen Diagnosemöglichkeiten (Öffnung der Bauchhöhle, Mikroskopie, Gewebeentnahme und -analyse) (ebd., S. 216) führten auch dazu, dass plötzlich das Geschlecht von Menschen problematisiert wurde, an deren geschlechtlicher Eindeutigkeit zu zweifeln vorher niemand gewagt hätte (ebd., S. 217). Der äußerliche Entsprechungsdruck zog nicht selten Zwangsauflösungen von Ehen nach sich. ${ }^{7}$

\section{Geschlechtsentwicklung als komplexes Interaktionsgeschehen}

Der selbstverständliche Umgang mit einer zweigeschlechtlichen Matrix erweist sich in biologisch-medizinischer Forschung mittlerweile als hochproblematisch: Die an der Geschlechtsdetermination beteiligten Vorgänge können in einem binärgeschlechtlichen Interpretationsrahmen nicht angemessen erfasst werden.

Voß (2010) führt das am Beispiel der sogenannten Gen-Expressionsanalyse vor. Untersucht werden in solchen Analysen nach Geschlecht (d.h. nach Geschlechtschromosomen) unterschiedene Proben mit embryonalen Geweben, aus denen sich z. B. Hoden und Eierstöcke entwickeln. »Jede bereits vor der Expressionsanalyse vorgenommene geschlechtliche Einteilung in (zwei) Gruppen (anhand welcher Merkmale auch immer) führt dazu, dass andere Interpretationen der Resultate als binär-geschlechtliche nicht möglich sind «(Voß, 2010, S. 294). Die anzunehmenden individuellen Unterschiede der Transkripte sind sehr viel größer als die Unterschiede in den Proben einer Geschlechtsgruppe, werden aber durch die Verwendung von Mischproben nicht sichtbar. Gene werden »nicht in einem On-Off-Modus entweder exprimiert oder nicht exprimiert [...]; vielmehr erfolgt die Expression oft in unterschiedlicher Quantität « (ebd., S. 293). In dieser Hinsicht müssten z. B. gewebsspezifische Konzentrationsgradienten in

7 Z.B. Foucault (2012). Weitere Hinweise bei Voß (2010, S. 216, Fn. 530). 
Betracht gezogen werden, die ihren Grund in einer individuell stärkeren Zellaktivität oder auch in äußeren Bedingungen haben können und deren Wirkungen wiederum nicht nur auf ein Gewebe beschränkt bleiben (ebd., S. 293). Die binär-geschlechtliche Fixierung im Konzeptualisierungs- und Operationalisierungsprozess zeigt sich auch an der Orientierung an den für die Hodendeterminierung verantwortlich gemachten Gen-Abschnitten.

\begin{abstract}
»Wissentlich oder unwissentlich setzen solche Untersuchungen bereits voraus, dass sich die Expressionsmuster in Eierstock- oder Hodengewebe dichotom geschlechtsspezifisch unterscheiden. [...] Schon gegenüber Genen, die in Eierstock- und Hodengewebe gleichermaßen exprimiert werden, sind so angelegte Expressionsanalysen $>$ blind <, auch wenden sie sich der eigentlichen Frage nach der Geschlechtsentwicklung und ob diese stets in eine von zwei angenommenen Richtungen verlaufen muss, nicht zu $\ll$ (ebd., S. 296).
\end{abstract}

Hinzu kommt, dass von der Vielzahl der - neben den vermeintlichen Geschlechtschromosomen - in der Phase der Geschlechtsdetermination exprimierten Gene gerade etwa 100 identifiziert und teilweise näher beschrieben sind. Bisherige Grundannahmen wie die Initialfunktion des Gens SRY für die Hodendetermination werden immer fraglicher.

Auch ein verändertes Verständnis des Gens macht es nötig, sich von der dichotomen Geschlechtsauffassung zu lösen. So weiß die biologisch-medizinische Forschung heute, »dass DNA keinen beständigen, unveränderlichen >Text< darstellt, den es nur zu >lesen< gilt, vielmehr ist sie innerhalb des Organismus in Veränderung begriffen «(Voß, 2010, S. 298). Damit die Genprodukte überhaupt eine Wirkung entfalten, bedarf es zudem komplexer und wechselseitiger Kommunikations- und Interaktions-, Übersetzungs- und Umbauprozesse. Mit dem Begriff Gen wird lediglich ein DNA-Bereich benannt, jedoch nichts über diese Prozesse und das entstehende Ergebnis (Genprodukt, Protein) - sowie seine »Lokalisation, Aktivität und Reaktivität « (ebd., S. 302) ausgesagt. An eine mögliche Identifizierung der an der Geschlechtsdetermination beteiligten Gene wird sich also die notwendige Analyse von Struktur, Modifikationen, Interaktionen und Funktionen jedes 
der von diesen Genen exprimierten Genprodukte anschließen müssen (ebd., S. 293).

Die Eierstockentwicklung wurde lange als rein passive Folge einer ausbleibenden Hodenentwicklung begriffen. Die Ähnlichkeit dieser Annahme mit frühen Reduktionstheorien, nach denen es sich bei der Frau lediglich um einen nicht zu voller Entwicklungsreife gelangten Mann handelt, ist nicht zu übersehen. Für die Eierstockentwicklung wird mittlerweile nicht nur ein eigener Signalweg angenommen, sondern es scheint eine Vielzahl von Genen aktiv an der Eierstockentwicklung beteiligt zu sein (Voß, 2011, S. 154f.).

Vor der jeweiligen Differenzierung besitzen alle Embryonen sieben Wochen lang eine indifferente geschlechtliche Keimdrüsenanlage, die über die Hormonausschüttung die weitere Geschlechtsausprägung steuert. Die für die Differenzierung verantwortlichen Hormone unterscheiden sich dabei individuell vor allem hinsichtlich der Menge und des Zeitpunkts ihrer quantitativen Ausschüttung (ebd., S. 136). Die Interaktion zwischen Keimdrüsen und Hormonen, die individuellen und graduellen Unterschiede, aber auch die enorme Abhängigkeit dieser Prozesse von äußeren Faktoren (z. B. dem mütterlichen Organismus) in der Embryonalentwicklung erklärt die große Bandbreite möglicher geschlechtlicher Konfigurationen.

Angesichts dieser differenzierten und diffizilen Forschungslage zur Frage, was die menschliche Geschlechtlichkeit überhaupt ausmacht, kann mit Voß zu Recht gefragt werden:

»Ist der Chromosomensatz das Entscheidende? Sind es die einzelnen Gene und die vielen daraus gebildeten Produkte? Von welcher Quantität eines gebildeten Produktes an gilt ein Mensch als > weiblich<, wann als > männlich<? Sind es Keimdrüsen, die eindeutig sein sollen - oder müssen sie auch Keimzellen produzieren (können)? Muss ein >Mann< über funktionsfähige Samenzellen verfügen, und muss eine $>$ Frau $<$ neben der Möglichkeit, Eizellen zu produzieren, auch die >inneren Genitalien $<$ aufweisen, einen Embryo entwickeln und austragen können? Oder ist doch schlicht das äußere Erscheinungsbild der Genitalien - insbesondere Penis, Hoden und Vagina das Typische? Alle diese Merkmale zusammen werden bei keinem einzigen Menschen in eine >eindeutige Richtung >männlich< oder > weiblich< zusammenspielen « (ebd., S. 163). 


\subsection{Geschlecht zwischen Konstruktivismus und Realismus}

Das » natürliche Geschlecht « eines jeden Menschen stellt sich in biologisch-medizinischer Perspektive als nicht so eindeutig dar, wie allgemein angenommen. In ihrem Durchgang durch die Geschlechtermodelle zeigen Laqueur (1992), Honegger (1991) und vor allem Voß (2010), dass die empirische Füllung der Geschlechterkategorien (in biologischmedizinischer Perspektive) und die normativen Implikationen für die Geschlechterrolle (und die Sexualität) keineswegs die Ergebnisse eines steten Erkenntnisfortschritts und rein binnenwissenschaftlichen Fortschreibungsprozesses sind. Die Vorstellung von dem, was Geschlecht ist, welche Arten von Geschlecht lesbar und lebbar sind, waren vielmehr immer in hohem Maße von den allgemeinen gesellschaftlichen Vorgaben abhängig.

\section{Intersex als Intelligibilitäts-Grenze}

Die Unterscheidung zwischen dem biologischen Geschlecht (sex) und dem sozialen Geschlecht (gender) ermöglichte einst die Entkoppelung von sozialer Rolle und natürlichem Geschlecht. Die Unterscheidung half, Naturalisierungen zu entlarven und damit verbundene normative Engführungen aufzubrechen.

Intersex verweist auf die Grenzen dieser Unterscheidung, insofern diese an der Annahme einer zweigestaltigen Grundkonfiguration menschlicher Geschlechtlichkeit festhält. »Wenn die Materialität des Geschlechts [sex] im Diskurs abgegrenzt wird, dann wird diese Abgrenzung einen Bereich des ausgeschlossenen und entlegitimierten $>$ sex $<$ hervorbringen « (Butler, 1995, S. 40), einen uneindeutigen Bereich, der konsequenterweise der geschlechtlichen Norm angeglichen werden muss, um kulturell lesbar zu werden. Die Zuweisung von Intersex ist diesem Verständnis folgend kein Definitionsakt zur Unterscheidung von Geschlechtlichkeiten, sondern ein Ausschluss aus der Intelligibilitäts-Matrix überhaupt, in der zu verbleiben es die Zuordnung zu einem von zwei Geschlechter-Polen verlangt. Es entsteht ein System der Zwangsheterosexualität, d. h. ein System, in dem jemand »als sexuelle 
Person nicht außerhalb der Begriffe der Heterosexualität lesbar [ist] « (Butler, 2013, S. 66). Dieses System greift schon mit der Geschlechtsidentifizierung nach der Geburt. Als gesellschaftliche Norm findet es seinen folgenreichsten Ausdruck im Personenstandsrecht, das jedem_r Bürger_in die Zuordnung zu einer von zwei möglichen Geschlechtskategorien abverlangt.

Butler radikalisiert und überwindet die Sex-gender-Unterscheidung, indem sie sex als gender (Heß, 2005, S. 304), d. h. körperliches als soziales Geschlecht interpretiert. Schon »[d]ie Unbestreitbarkeit des > biologischen Geschlechts< oder seiner > Materialität< > einzuräumen $<$ hieße stets, daß man irgendeine Version des >biologischen Geschlechts < , irgendeine Ausformung von > Materialität< anerkennt « (Butler, 1995, S. 33). Geschlecht wird uns überhaupt erst zum Gegenstand durch Definitions- und damit Ausschlussarbeit: Ausgewählte, biologisch-medizinisch fassbare Merkmale werden zusammengebunden und als weibliches oder männliches oder - in der Orientierung an diesem Kategorienkorsett - unlesbares (Zwischen-)Geschlecht verstanden.

Butler bestreitet mit ihrer These der Diskursivität von Geschlecht nicht die Materialität desselben; sie begreift Materie »jedoch nicht als de[n] Ort der Oberfläche [...], sondern als ein[en] Prozeß der Materialisierung, der im Laufe der Zeit stabil wird, so daß sich die Wirkung von Begrenzung, Festigkeit und Oberfläche herstellt, [ein Ort] den wir Materie nennen « (ebd., S. 32). Materie, in diesem Sinne verstanden als Art, wie uns etwas gegenständlich wird, ist nicht anders zu haben als vorstrukturiert durch unseren Begriff von ihr. Materie - und damit auch geschlechtliche Materialität - wird diskursiv konstituiert. Geschlecht ist in seiner Materialität nicht zugänglicher und selbstverständlicher als Geschlechtsverhalten und Sexualität, sondern selbst immer schon kulturell-diskursiv überformt, historisch wandelbar und in seinem jeweiligen Verständnis von bestimmten Interessen geprägt.

Die Antwort auf die Frage nach der ursprünglichen Entstehung der hermetischen heterosexuellen Matrix ist umstritten. Bestimmte in der Vormoderne der Stand und nicht die Frage nach dem Wesen das Nachdenken und Reden über »Mann « und »Frau «, so vollzieht sich mit dem Übergang zur Moderne eine eigenartige Fixierung auf die nun naturwissenschaftlich bestimmte Geschlechtlichkeit. Paradox 
erscheint dieser Umstand insofern, als die wirtschaftliche, wissenschaftliche, künstlerische, politische, erzieherische und religiöse Entfaltung und Leistungsfähigkeit vorher zu keiner Zeit rein geschlechtlich codiert waren (Nassehi, 2003; Karle, 2006, S. 22).

Den Mechanismus, der die hermetische, zweigestaltige Geschlechtermatrix hervorbringt, erstarren lässt und erhält, kennzeichnet Butler als Performativität. Das ist das beständige, zitierende Wiederholen von geschlechtlichen Normen. »[I]n dem Ausmaß, in dem [die Performativität] in der Gegenwart einen handlungsähnlichen Status erlangt, verschleiert oder verbirgt sie die Konventionen, deren Wiederholung sie ist $\ll(1995$, S. 36).

Es geht Butler jedoch nicht um die Auflösung oder Leugnung von Geschlechtlichkeit, sondern um die Auflösung ihrer Engführung. Dekonstruktion ist dabei nicht Destruktion (2013, S. 67). Ein differenzierteres Verständnis von Geschlecht stellt nicht in erster Linie die Leistungsfähigkeit von Geschlecht im Rahmen bestimmter Überprüfungen des Menschen infrage. Unbestreitbar kann ein Bestand an bestimmten körperlichen Merkmalen unter den Oberbegriffen »Mann « und »Frau « zusammengefasst werden. Aufgrund der faktischen Vielgestaltigkeit der körperlich-geschlechtlichen Morphologie erweist sich dieses Begriffspaar jedoch als nicht sehr präzise Kategorisierung. Bestimmend muss vielmehr die Frage sein, wer durch die gegenwärtig dominante Vorstellung von Geschlecht und die daran orientierte Gesellschaftsgestalt ausgeschlossen wird bzw. inwiefern eine bestimmte Auffassung von geschlechtlicher Identität zur Voraussetzung legitimen, nicht-korrekturbedürftigen Menschseins erhoben wird. Die normierte Geschlechtsidentität darf nicht zu einer »kulturellen Voraussetzung des Menschseins « (ebd., S. 66) werden. Intersexe lassen uns dessen gewahr werden: Es gibt Menschen, die diese aus einer sexuierten gesellschaftlichen Norm gewonnene Voraussetzung nicht selbstverständlich erfüllen: Sie werden » als eingeschränkt menschlich erkannt, und diese Form der eingeschränkten Anerkennung führt nicht zu einem bewältigbaren Leben « (Butler, 2009, S. 10f.). 


\section{Die Widerständigkeit der Wirklichkeit - eindeutiges Geschlecht?}

Gegen Butlers Fassung von Materialität regt sich mitunter Widerstand vonseiten feministischer naturwissenschaftlicher Theoriebildung. ${ }^{8}$ Butlers prinzipielle Abkehr von der Geschlechterdifferenz mit Hinweis auf ihren Konstruktcharakter berge nicht nur die Gefahr, durch die Nivellierung der Differenz in phallogozentrische (Irigaray, 1991), d.h. androzentrische Denkmuster zurückzufallen. In der Auflösung des geschlechtlichen Subjekts löse sich auch der kritische Standpunkt auf, von dem Dekonstruktionsarbeit überhaupt ihren begründeten Ausgang nehme und sich politisch weiterdenken lasse.

In kritischer Auseinandersetzung mit Butler verlagert Karen Barad die Konstruktion von dem sich sozial ereignenden und sich selbst stabilisierenden zitatförmigen Performanz-Akt in die Materie selbst. In ihrer agentiell-realistischen Bestimmung ist »Materie Substanz[, aber] in ihrem intraaktiven Werden - kein Ding, sondern eine Tätigkeit, eine Gerinnung von Tätigsein. Materie ist ein stabilisierender und destabilisierender Prozeß schrittweiser Intraaktivität « (Barad, 2012, S. 40). Materie bestimmt, wie sie sich diskursiv materialisiert, oder: Matter matters. Die Agenten des Materialisierungsprozesses bestimmt Barad näher als Apparate, das sind »materiell-diskursive Praktiken - kausale Intraaktionen, durch die sich die Materie schrittweise und differentiell artikuliert, wobei das materiell-diskursive Feld von Möglichkeiten und Unmöglichkeiten in der fortlaufenden Dynamik der Intraaktivität, die das Tätigsein ist, rekonfiguriert wird « (ebd., S. 73).

Die Erhebung der Materie zum eigentlichen Akteur der Materialisierung bei Barad erscheint als bloße Verschiebung der Handlungsinstanz, ohne jedoch das konstruktivistische Grundproblem zu klären, wer sich des Konstruktcharaters von Materie überhaupt bewusst werden/sein soll, wenn es keinen subjektartigen Bewusstseinskern oder einen verlässlichen Zugang zur Wirklichkeit jenseits der Konstruktion

8 Z.B. Grosz (2005), Barad (2012), Kirby (1997): »The anatomical body emerges as reality's harshest truth in the very attempt to dissolve its substance and the accompanying notions of sreality and sreferences through which it is made manifest« (S. 71). Zu den philosophischen Problemen des auch Butlers Gedanken inhärenten Nominalismus vgl. z. B. Hull (2006). 
und jenseits rein performativer Akte (Selbstanwendungsproblem des Konstruktivismus) gibt.

Butler (2013) reagiert auf den Relativismus-Vorwurf und unterstreicht immer wieder, dass es zwar einen materiellen, nicht diskursiven Körper gibt. Jede Körperbeschreibung scheitert jedoch an der Eigensinnigkeit bzw. »Persistenz «, die der Materialität selbst innewohnt (S. 67). Wir erfassen den Körper in unseren Beschreibungen (seien sie soziologischer, biologischer oder anderer Art); der (Geschlechts-)Körper geht jedoch in keiner dieser Körperbeschreibungen auf, sondern widersetzt sich jeder Letzterklärung.

»[D]ass wir wissenschaftlich, konzeptionell, aber auch überhaupt sprachlich so auf Wirklichkeit Bezug nehmen, dass wir mit ihr zwar immer nur in Form unserer eigenen Entwürfe umgehen können, dieser Umgang aber durch die Widerständigkeit des Wirklichen seinen Realismus erhält, unterläuft gängige Vorstellungen der Differenz von >Wirklichkeit< und $>$ Deutung $<$, von $>$ Subjektivismus $<$ und $>$ Objektivismus $<$, von $>$ intern $<$ und $>$ extern $<\ll($ Evers, 2014, S. 97f. $) .9$

Gerade in der Begegnung mit Intersex werden wir auf mehrfache Weise dessen ansichtig, was als Widerständigkeit der Wirklichkeit bezeichnet wurde. Intersex verweist einerseits darauf, dass biologische Geschlechtlichkeit nicht in einer binären Geschlechtermatrix aufgeht. Unser kategorialer Zugriff scheitert an der fassbaren geschlechtlichen Realität, die in ihrer Vielgestaltigkeit einer binären Konzeptualisierung widerstrebt und jeden jeweiligen Zugriff in seinem Letztbestimmungsanspruch scheitern lässt. Intersex widerstrebt in diesem Verständnis andererseits auch jeder radikal-konstruktivistischen Auffassung. Die Möglichkeit einer negativen Bewährung an der Wirklichkeit setzt eine perspektivenunabhängige Wirklichkeit im Sinne eines schwachen ontologischen Realismus voraus: Biologisch-medizinische Aussagen in Bezug auf die geschlechtliche Materialität sind möglich und bewähren sich an einer

9 Evers entwickelt ein Modell, nach dem die Wirklichkeit in »drei irreduziblen Hinsichten« unterteilt wird: als »Widerständigkeit«, als »Macht des Wirklichen« und als Bedingung der Möglichkeit von Wirklichkeit, d. h. ihrem »Woher« und »Woraufhin«. 
irgendwie gearteten Wirklichkeit - aber gerade nicht als dichotom strukturierter Interpretationsrahmen für Geschlecht. ${ }^{10}$ Die gängigen Geschlechterkategorien scheitern an der individuellen biologischen Beschaffenheit von Geschlecht. Sie scheitern schließlich am Selbsterleben nicht nur von Intersexen, sondern eines jeden Menschen, der körperliches Geschlecht, Geschlechtsidentität und sexuelle Orientierung nicht in der Weise in Kongruenz zu bringen vermag, wie das essenzialistische Bestimmungen von Mann und Frau voraussetzen.

\section{Geschlecht und Fortpflanzung - unbestreitbare Geschlechtsfunktion?}

Ein häufig geäußerter Einwand gegen die Mobilisierung der Geschlechterkategorien lautet, dass der Mensch als sich geschlechtlich fortpflanzendes Wesen nun einmal über eine bestimmte anatomische Ausstattung verfügen müsse, die ihm dies ermögliche. Dazu ist zweierlei zu sagen: Nicht alle Formen von Intersex gehen mit Fortpflanzungsunfähigkeit einher. Ein pathologisierendes Verständnis geschlechtlicher Nichteindeutigkeit ist unter Berufung auf die gegebenen oder nicht gegebenen reproduktiven Fähigkeiten also nicht ohne Weiteres möglich. Darüber hinaus ist es insgesamt problematisch, ein mögliches Verständnis des Menschen und seiner Geschlechtlichkeit auf Fortpflanzungszwecke festzulegen. Wie inkonsequent eine solche reproduktive Engführung ist, wird schon an der Tatsache deutlich, dass es Frauen (und Männer) gibt, die ihre reproduktiven Fähigkeiten nicht oder anders in Anspruch nehmen.

»Behaupten wir, sie seien keine Frauen? Wenn wir sagen, Frauen unterscheiden sich von Männern durch diese Fähigkeit, es sich aber heraus-

10 Wie oben bereits deutlich geworden ist, bedeutet die Aufgabe des zweigeschlechtlichen Interpretationskorsetts nicht das Ende biologisch-medizinischer Geschlechterforschung. Vielmehr wird so ein wissenschaftsexterner Wert aus dem vorempirischen Entdeckungszusammenhang getilgt, der eine gegenstandsadäquate Konzeptualisierung und Operationalisierung verhindert und damit den Begründungszusammenhang, also die empirische Arbeit, maßgeblich fehlleitet und beeinträchtigt. 
stellt, dass diese Fähigkeit nicht wesentlich dafür ist, wer sie sind, dann befinden wir uns in einem kulturellen Akt: Wir setzen eine kulturelle Norm der Reproduktion zur Bestimmung eines biologischen Unterschieds fest $\ll$ (Butler, 2013, S. 66).

Die Gruppe derer, die auf die Inanspruchnahme ihrer reproduktiven Fähigkeiten verzichtet, ließe sich erweitern um die hohe Zahl derer, die » ungewollt kinderlos « bleiben (Voß, 2011, S. 130). Hinzu kommen all die reproduktionsmedizinischen Eingriffsmöglichkeiten und Verfahren, die das Spektrum möglicher Erzeuger- und Elternschaft in den letzten Jahrzehnten enorm verändert haben und weiter verändern werden.

Vor diesem Hintergrund muss betont werden: Die für die Erhaltung der menschlichen Art notwendige geschlechtliche Fortpflanzung stellt eine Gattungseigenschaft dar, von der »nicht auf die individuellen Eigenschaften eines konkreten Menschen geschlossen werden « (ebd., S. 132) kann. Die Entkoppelung von Geschlecht und Reproduktion bedeutet nicht zwangsläufig Beliebigkeit, sondern stellt gegenüber identitären Zuschreibungen vielmehr das individuelle Selbsterleben in den Vordergrund: Ich bin, der_die ich bin. Ich kann mich als Frau fühlen, obwohl ich über verschieden-geschlechtliche Keimdrüsen verfüge. Ich kann mich weder eindeutig als Frau noch als Mann fühlen, obwohl mein Chromosomensatz »eindeutig « ist. Schon ein Blick auf die Alltagsbegegnung zwischen Mann und Frau bestätigt diese Skepsis gegenüber dem vorschnellen reproduktiven Fehlschluss, handelt es sich hier doch oft $\gg$ mehr [um] eine vage Idee der Fortpflanzungsfähigkeit, die aus dem Erlernten, was $>$ weiblich $<$ oder $>$ männlich $<$ sei, auf konkrete Menschen übertragen wird, als $[. .$.$] um eine validierte Tatsache [\ldots] \ll$ (ebd., S. 131).

\subsection{Zwischenfazit}

Die biologisch-medizinische Beschäftigung mit Intersex zeigt, dass die Annahme einer binär codierten geschlechtlichen Eindeutigkeit problematisch ist. Der Versuch, Intersex als Zwischengeschlechtlichkeit in eine zweigeschlechtliche Matrix einzuzeichnen, scheitert und nötigt deshalb zu einer grundlegenden Revision des Verständnisses von Geschlecht. Ein gegenstandssensibleres Verständnis zeigt: Das biologi- 
sche Geschlecht ist nicht selbstverständlich entweder männlich oder weiblich, und es ist immer nur innerhalb eines bestimmten Interpretationsrahmens eindeutig. In biologisch-medizinischer Perspektive stellt sich biologisches Geschlecht als Kontinuum einer großen Breite möglicher biologischer Geschlechtlichkeiten dar, die sich eher individuell als binär-kategorial oder qualitativ unterscheiden. Geschlecht ist in seiner individuellen Ausprägung nur bedingt eindeutig, eher konstitutiv vieldeutig. Das zeigt sich nicht erst in der phänotypischen Ausprägung der Geschlechtsmerkmale. Die vermeintlich eindeutige Geschlechtlichkeit wird schon auf molekulargenetischer Ebene fraglich, wenn man ernst nimmt, wie komplex und vielfältig die bei der Geschlechtsdetermination involvierten Kommunikations- und Interaktions-Prozesse auf zellmolekularer Ebene und zwischen Organismus und Umwelt sind.

Wenn ferner Krankheit durch den »Verlust an Freiheitsgraden sowie eine Reduktion oder Auflösung des Form- und Gestaltniveaus des jeweiligen Patienten und seiner Lebensführung « (Rattner \& Danzer, 2009, S. 185) charakterisiert ist, dann ist der bisherige konzeptionelle und therapeutische Umgang mit Intersexen mehr als fragwürdig: Eine generelle Pathologisierung von Intersexen erscheint angesichts der Lebbarkeit der zahlreichen Formen von Geschlechtlichkeit unhaltbar. Keine Definition von Krankheit ist jemals nur eine rein medizinische Aussage, sondern immer auch Abbild des komplexen gesamtgesellschaftlichen Gefüges von weltanschaulichen und damit handlungsleitenden Grundannahmen.

Ein Blick auf die Geschichte der medizinisch-biologischen Geschlechterforschung zeigt, dass das Geschlechterverständnis alles andere als ein überzeitlicher Konsens ist. Die Forschungsgeschichte offenbart zugleich die Schwierigkeit, falsche Grundannahmen auszumachen und in ein konstruktiv-kritisches Gespräch zu überführen. So stellt die Entwicklung der modernen Wissenschaft zunächst nicht etwa eine Befreiung dar, sondern die Durchsetzung einer exklusivistischen, heteronormativen ${ }^{11}$ Geschlechterkonfiguration unter Berufung auf natürliche

11 Das mit Heteronormativität bezeichnete Denken blendet nicht nur die Bandbreite geschlechtlicher Morphologie aus, sondern bewertet auch Geschlechtsidentität, Geschlechtsrolle und sexuelle Orientierung anhand der vermeintlichen heterosexuellen Grundkonfiguration eines jeden Menschen. 
Gegebenheiten: Was der Mensch immer schon zu sein schien, konnte nun in den körperlichen Tiefenschichten und mit vermeintlich schlagender Eindeutigkeit nachgewiesen werden.

Konstruktivistische Überlegungen dazu, was von den Geschlechterkategorien zu halten ist, gewinnen vor diesem Hintergrund besondere Relevanz. Butler betont, dass es keinen feststellbaren materiellen Kern gibt, der nicht immer schon diskursiv überformt wäre. Materialität auch die Materialität von Geschlecht - ist angemessener verstanden als das, was in seiner letztlichen Nichtfeststellbarkeit das (Geschlechter-)Begriffssystem prinzipiell offenhält. Anstelle einer Leugnung oder Ausblendung von Materialität ist also auf die Einsicht zu verweisen, dass jede Bezugnahme auf sie begriffliche Arbeit voraussetzt, die ihrerseits eine Geschichte hat und in kulturelle Zusammenhänge eingebettet ist. Im Zusammenhang mit Intersex erweist es sich in konstruktivistischer Perspektive als besonders problematisch, dass jede Bestimmung dessen, was ein gesunder, geschlechtlich-eindeutiger Körper ist, mit Ausschlüssen einhergeht. Die der Konstitution des »notwendigen Bereichs von Körpern « (Butler, 1995, S. 16) inhärente normative Dimension legt immer auch fest, was nicht sein soll, was nicht denkbar und nicht lebbar ist. 


\section{Intersex in theologischer Perspektive}

Intersex erweitert das Spektrum biologisch denkbarer, weil lebbarer Geschlechter und stellt damit die Annahme einer starr dichotomen Geschlechterkonfiguration infrage: Gott schuf Menschen nicht nur als Mann und Frau, die geschlechtliche Morphologie ist weitaus vielgestaltiger. Eine Theologie - verstanden als Wissenschaft unter Wissenschaften - kann nicht an den Erkenntnissen der nicht-theologischen Wissenschaften vorbei betrieben werden. Sie muss sich den Anfragen, die das allgemeine Wirklichkeitsverständnis betreffen, kritisch zuwenden, ${ }^{12}$ und sie muss sich in den Aussagen irritieren lassen, für die sie

12 Die Frage, inwieweit sich die Theologie von nicht-theologischen Erkenntnissen korrigieren lassen muss, erfordert eine wissenschaftstheoretische Verhältnisbestimmung, die an dieser Stelle unterbleiben soll. Für das hier vorausgesetzte Verhältnis von Theologie und nicht-theologischer Wissenschaft nur so viel: Als konstitutiv relationales und soziales Wesen findet sich der Mensch immer schon als zum Handeln befähigt und genötigt vor. Das im christlichen Glauben gegebene umfassende Wirklichkeitsverständnis fordert die heilsame Gestaltung aller dem Menschen immer schon vorgegebenen Grundverhältnisse, d. h. des Selbst-, Welt- und Gottesverhältnisses. Das mit der Gestaltung dieser Relationen befasste vernünftige Selbstbewusstsein ist nach christlichem Verständnis nicht Grund seiner eigenen Erschlossenheit. Es kann nur die ihm gewährten Möglichkeiten in Anspruch nehmen. Im Gottesbezug, d. h. in der Anerkenntnis Gottes als des alles konstituierenden Schöpfungsgrundes finden alle geschöpflichen Bezogenheiten zu ihrer möglichen Höchstgestalt: Die Vernunft erkennt sich als geschöpfliche, nicht durch sich selbst geschaffene, und damit endliche, in ihrer Leistungsfähigkeit begrenzte Vernunft. Im Schöpfungsrahmen als dem ihr zugestandenen Gestaltungsraum besitzt die geschöpfliche Vernunft in christlicher Perspektive 
allgemeine, glaubensunabhängige Evidenz beansprucht. Die Theologie ist deshalb also zunächst zu einer selbstkritischen Prüfung ihrer anthropologischen Grundannahmen und damit auch der als natürlich vorausgesetzten Geschlechterkonfiguration aufgefordert.

Das durch Intersex motivierte Nachdenken über Geschlecht zerfällt in unterschiedliche einzelwissenschaftliche Perspektiven. Es handelt sich in gewisser Weise um ein essentially contested concept ${ }^{13}$. Der Beitrag der Theologie im Ringen um ein angemessenes Verständnis von Geschlecht kann - wie gerade festgestellt - nicht in einer alternativen empirischen Füllung des biologisch-medizinischen Begriffs von Ge-

andererseits auch Deutungs- und Gestaltungsfreiheit. Die Explikation und Gestaltung der immanenten, geschöpflichen Bezogenheiten, die ihren Ausdruck in einer differenzierten sozialen und kulturellen Welt finden, versehen unterschiedliche wissenschaftliche Disziplinen. Die Frage nach dem Möglichkeitsgrund des Relationengefüges, auf den hin alle Relationen immer transparent sind, ist ein Erkenntnisinteresse der Theologie. Ihre Erkenntnisse wirken sich damit freilich auch auf den Deutungs- und Gestaltungsanspruch aller Relationen aus, nicht jedoch im Sinne einer theologischen Zensur empirischer Arbeit. Christlich-theologisch kommt das z. B. in der Frage nach der Bestimmung des Menschen zur Sprache. Theologie, die nicht exklusiv mit bestimmten (theologischen) Einzelgegenständen befasst ist, sondern mit der sich aus der Transzendierung des Dass, Warum und Wohin ergebenden Tiefe oder Qualität aller Gegenstände, ist in diesem Sinne auch diejenige Wissenschaft, die sich mit dem unser Denken, Wahrnehmen und Handeln leitenden Orientierungswissen auseinandersetzt. Mit der Geschöpflichkeit geht in theologischer Perspektive also nicht nur die Beschränkung der Vernunft einher, sondern auch die Ermächtigung der rechtgeleiteten geschöpflichen Vernunft, den für sie einsehbaren Strukturen der Wirklichkeit auch auf den Grund zu gehen. Die Regelmäßigkeiten und Strukturen der geschaffenen Wirklichkeit zu beschreiben, ist das Erkenntnisinteresse u.a. der Naturwissenschaften. Dass die z. B. in Form von Naturgesetzen oder anderen Kausalitäten beschreibbaren Phänomene nicht die Bedingung der Möglichkeit ihrer eigenen Verwirklichung sind - eine Frage, die sich die Naturwissenschaft nicht stellt und mit ihrem methodischen Instrumentarium gar nicht bearbeiten könnte -, verweist auch auf die prinzipielle Unabschließbarkeit des naturwissenschaftlichen Forschungsprojekts.

13 Gallie (1956) benennt damit abstrakte Begriffe, deren Intensionalität umstritten ist und um deren Deutungshoheit gerungen wird. Hier wird der Begriff im Sinne Schwöbels verstanden (2012, S. 149): »Essentially contested concepts confront us with the challenge to reveal the framework within which these concepts function and to describe their function in different frameworks in order to have a meaningful conversation about disagreements, agreements and possible convergences in the process of understanding. They open up the possibility of different understandings to complement or correct one another.« 
schlecht bestehen - in diesen Aussagen bleibt die Theologie angewiesen auf die empirisch-naturwissenschaftliche Arbeit zu Geschlecht. Ausgehend von der Möglichkeit einer Welt, in der es Biologie gibt ${ }^{14}$, kann theologisch jedoch gefragt werden, wie die in anderer wissenschaftlicher Perspektive feststellbare und nicht aufzulösende GeschlechterVieldeutigkeit zu interpretieren ist. Gerade die Nichtfeststellbarkeit des Menschen, die das Individuum vor allen geschlechtlichen Kategorisierungsversuchen (Mann und Frau) in den Vordergrund treten lässt, macht das nicht-theologische Nachdenken über Geschlecht transparent für ein weiterführendes Fragen: Als theologische Herausforderung rückt die faktische geschlechtliche Vieldeutigkeit in den Blickpunkt. Geschlechtliche Devianz beruht auf der Setzung eines Bereichs des Eindeutigen. Nur in Bezug auf einen solchen Bereich des Eindeutigen kann überhaupt von Intersex gesprochen werden. Dieses Verhältnis zwischen Eindeutigkeit und Vieldeutigkeit, in dem Intersex changiert entweder als mögliches individuelles Geschlecht anerkannt und keiner besonderen Thematisierung bedürftig oder als das aus einer bestimmten Ordnung geschlechtlicher Eindeutigkeit Ausgeschlossene -, soll theologisch bedacht werden. Ich nähere mich dem Problem anhand von drei Aspekten von Geschlechtlichkeit. Die Betrachtungsebenen können voneinander unterschieden werden, bedingen sich jedoch zugleich und können demzufolge nicht voneinander getrennt werden. Auch wenn der Fokus in den theologischen Unterkapiteln jeweils ein anderer ist, ist es deshalb nicht möglich, das in den jeweils anderen Teilkapiteln Gesagte ganz zurückzustellen und auszublenden.

In einem ersten Schritt soll mithilfe des Leibbegriffs dargestellt werden, wie die am Beispiel von Intersex und der biologisch-medizinischen Forschung zutage tretende geschlechtliche Vieldeutigkeit und Nichteindeutigkeit theologisch zu beurteilen ist. An die faktische letztliche Nichterschlossenheit des Menschen in seiner Leiblichkeit schließt sich die Frage nach der Zwangsläufigkeit einer auf der vermeintlichen geschlechtlichen Eindeutigkeit errichteten Geschlechterordnung an. Geschlecht tritt in diesem Sinne theologisch in den Fokus als menschlicher

14 Frei nach Link (2003, S. 117). Link spricht über die »Möglichkeit einer Welt, in der es Physik gibt«, steuert aber eine ähnliche Verhältnisbestimmung von Theologie und Naturwissenschaft an. 
Versuch, die Schöpfung zu ordnen und zu gestalten, der theologisch gerade in seiner Ambivalenz bedacht werden muss. In einem zweiten Schritt soll dieser Zusammenhang im Anschluss an Eilert Herms' Verständnis der Schöpfungsordnung (2004) bearbeitet werden.

Deutlich wird, dass sich eine heteronormative Engführung bei der Rede von Geschlecht aus theologischer Perspektive nicht rechtfertigen lässt, sondern dass diese mehr Flexibilität zulässt als die Annahme einer vermeintlich schöpfungsgemäßen zweigeschlechtlichen Ordnung. Die christlich-theologische Perspektive legt vielmehr ein nicht-exkludierendes Verständnis von Intersex-Phänomenen im Rahmen einer konstitutiv vieldeutigen, immer nur relativ eindeutigen geschaffenen Wirklichkeit nahe.

Die bedingungslose Forderung nach Eindeutigkeit bedarf der Abgrenzung eines Bereichs des konstitutiven Außen. Diese Vereindeutigungslogik, die zum Eindeutigkeitszwang werden kann, erscheint in theologischer Perspektive als hochproblematisch, fordert der christliche Glaube doch vielmehr anzuerkennen, dass auch Geschlechterordnungen unter einem letzten Vorbehalt stehen. Der fehlgeleitete, ausschließende Umgang mit Intersexen nähert sich gleichermaßen sowohl aus einem falschen Leibbegriff als auch aus einem falschen Verständnis menschlich-sozialer Ordnungsgestalten: Der Kampf gegen die eigene Unergründlichkeit im nicht-lesbaren Geschlecht des Anderen und die Vergötzung menschlicher Ordnungen wirken ineinander in dem leid- und todbringenden Zwang zur Eindeutigkeit. In einem dritten Schritt sollen die Ergebnisse des theologischen Nachdenkens über Geschlecht als Selbsterfahrungs- und Ordnungskategorie in diesem Sinne zusammengeführt und im Hinblick auf die Folgen, die sich aus ihrem Missverständnis ergeben, zugespitzt werden.

\subsection{Geschlechtliche Nichteindeutigkeit und das leibliche Selbsterleben}

\section{Der Mensch als leibhaftig relationales Wesen}

Der Leibbegriff erscheint als angemessener Ausgangspunkt, um die Selbsterfahrungsdimension der geschlechtlichen Vieldeutigkeit bzw. letztlichen Nichteindeutigkeit zu klären. Im Gegensatz zu substanzialistischen Denkfiguren bringt der Leibbegriff die konstitutive und viel- 
gestaltige » multirelational strukturierte « (Mühling-Schlapkohl, 2004, S. 260) Lebenswelt bzw. Erfahrungswirklichkeit des Menschen zum Ausdruck. In der phänomenologischen Tradition und der philosophischen Anthropologie benennt der Leibbegriff eine $\gg$ Dimension körperlichen Daseins [...], die nicht in einem objektivistischen oder materialistischen Körperverständnis aufgeht, sondern aufs engste mit der Kategorie der Erfahrung verbunden ist « (Alloa et al., 2012, S. 1). ${ }^{15}$ In diesem Verständnis ist der Leib nicht gegenständlich zuhanden, sondern »immer nur mitgegeben; als Bedingung von Erfahrung [...] nur miterfahren « (Alloa \& Depraz, 2012, S. 12; Husserl, 2008, S. 615). Ausgehend von der exzentrischen Positionalität des Menschen hebt Plessner die Differenz zwischen Leib und Körper in das Begriffspaar Körper-sein und Körper-haben (Schürmann, 2012, S. 217 über Plessner, 1975). In der Unterscheidung drückt sich die doppelte Vermitteltheit leiblicher Existenz aus, auf jedes Widerfahrnis aktiv und reflexiv reagieren zu können. Die konstitutive Exzentrizität des Menschen unterstreicht zudem,

15 Im Gegensatz zum nicht feststellbaren Leib bezeichnet Körper für Husserl (2008) die objektiven Aspekte der Leiblichkeit. Die Konstitution des Leibes sowie die Syntheseleistung, Körper und Leib »zusammenzuhalten«, schreibt er dem intentionalen, reflexiven Bewusstsein zu. Mit der Unterscheidung von Körper und Leib gibt Husserl den leibphilosophischen Begriffs-Rahmen für mehrere Schülergenerationen vor. Das Verständnis von Leib als letztlich entzogener, aber jeden Weltbezug stiftenden und als solcher erfahrenen »Handlungs- und Beziehungsmitte« (Kristensen, 2012, S. 25) präzisiert Merleau-Ponty in seiner Rede vom Körperschema (Merleau-Ponty, 1966, S. 121-127). Das implizite Körperschema kann verstanden werden als sedimentierte Erfahrung der Persistenz, der "Ständigkeit des Eigenleibes« (S. 114-118), die jedoch begrifflich unter Absehung der konkreten Leiberfahrung nicht feststellbar ist, sondern mehrdeutig bleibt. Im Körperbild nimmt das Körperschema eine explizite Form an. »Das Schema als Bild ist [... ] mein Leib als sichtbarer Leib für die Anderen « (Kristensen, 2012, S. 33). Wie ist nun der zwischenleibliche Bereich zu deuten? Im Gegensatz zu Merleau-Ponty (1966), der die Zwischenleiblichkeit als Begegnungsraum begreift, fokussiert Levinas $(2008,1986)$ die in der Zwischenleiblichkeit erfahrene Passivität, Alterität (im Selbst) (vgl. auch Bedorf, 2012, S. 68-80) und das Getrenntsein vom Anderen. Die Entzogenheit des Leibes steigert Henry ins Transzendentale, wenn bei ihm die Leiblichkeit »Bedingung der Möglichkeit des empfundenen mundanen Körpers` (Henry, 2000, S. 176), d. h. aller materiellen Körper in der Welt ist« (Scheidegger, 2012, S. 104). Die entrückte Leiblichkeit wird für Henry als Konstituens nicht nur meines Leibes, sondern meiner Welt vor allem in ihrer begrenzenden und begrenzten Widerständigkeit erfahren (Scheidegger, 2012, S. 104; Henry, 1965, S. 184). 
dass es ihm unmöglich ist, kein Verhältnis zu seinem Körper und Leib zu haben, denn dieses ist konstitutiv relational in all seine Lebensvollzüge eingebunden (Schürmann, 2012, S. 220). Dieses Verständnis erweist sich auch für eine theologische Entfaltung der im christlichen Glauben erfahrenen grundlegenden menschlichen Relationalitäten als geeignet.

Leiblichkeit beschreibt in theologischer Perspektive die spezifische Seins- und Selbsterfahrungsweise des Menschen in dem als Schöpfung verstandenen Weltzusammenhang: Leiblich ist der Mensch er selbst als Geschöpf Gottes im Miteinander mit anderen Geschöpfen. Der Begriff des Leibes fokussiert das natürliche Substrat dieser konstitutiven Relationen: der Beziehung des Menschen zu sich selbst, zu seinen Mitgeschöpfen und zum Schöpfergott als seinem Möglichkeitsgrund. Der Leib als Ganzheitsbegriff bezeichnet dabei aber nicht nur den materiellen Körper, sondern alle physisch-psychisch-seelischen Prozesse.

Als Mensch bin ich immer mein Leib. Leibhaft erfahre ${ }^{16}$ ich mein individuelles Da-Sein in der Welt, meine Individualität und die Kontinuität meines Ichs, schließlich die Freiheit, die Relationen in denen ich stehe, zu gestalten: Leiblich erfahre ich mich als überhaupt erst befähigt zum Handeln im Rahmen des Weltzusammenhangs, in den ich mich immer schon eingebunden weiß. ${ }^{17}$

\section{Der Leib als das Andere meiner selbst}

Ich habe einen Körper und bin doch mein Leib, ${ }^{18}$ d. h. ich erfahre $\gg$ das Natürliche [als] das Andere [m] einer selbst « (Koch, 1978, S. 298).

16 Der hier und im Folgenden vorausgesetzte Begriff»Erfahrung « impliziert gegenüber dem »Erlebnis«, sowohl erfahren zu müssen als auch Erfahrungen zu machen (Lange, 2002, S. 305f.). »Erfahrung ist eigenständiger Umgang mit widerfahrender Wirklichkeit« (ebd.), setzt also Intentionalität und Selbstbezüglichkeit voraus.

17 Zum Leib als »Medium menschlicher Freiheit und Abhängigkeit« vgl. Herms (1991, S. 33-39).

18 Die hier entfaltete Unterscheidung Leib-Sein und Körper-Haben wurde von Koch (1978, S. 298-305) übernommen, der diesen Gedanken vor allem aus der Auseinandersetzung mit Husserl, Plessner und Merleau-Ponty gewinnt. Zudem wird Leib als Ganzheitsbegriff und Körper verwendet, im Gegensatz zu dem, was vom Leib phänomenal bzw. gegenständlich wird. Der Leib geht nicht im Körper - im Sinne menschlicher Körperbegriffe - auf. 
Besonders in der Differenzerfahrung, » $\mathrm{i}] \mathrm{n}$ der Hemmung oder Beeinträchtigung, in der sich der Körper als etwas widerständig Störendes bemerkbar macht « (S. 299) oder in der »kontingenten Differenz von Selbst- und Fremdwahrnehmung « (Ringleben, 2002, S. 219), wird die eigene Leibhaftigkeit als Körperlichkeit gegenständlich, z. B. als Beinoder Kopfschmerz.

Die Erfahrung des Leibes als des »natürlich Andere[n], mit dem ich selbst zugleich identisch bin « (ebd., S. 218) und die Notwendigkeit, ein Verhältnis dazuzugewinnen, begründet auch meine spezifische Beziehung zu meinen Mitgeschöpfen. Erst die Erfahrung der Andersheit am eigenen Leib ist es, die ein Verständnis der Andersheit des Anderen als Anderem ermöglicht. ${ }^{19}$

» [D]as für alle Interaktion beanspruchte Anderssein der Anderen haftet am je leibgebundenen Eigenerleben und der je leiblich vermittelten Individualperspektive auf die gemeinsame Welt. [...] Von der Leiblichkeit des je eigenen, mithin immer selbsttätig-freien Erlebens und Handelns her bestimmt sich die Verschiedenheit der Individuen bei Gleichbeit der Freiheit $\ll$ (Dierken, 2005, S. 492).

Das eigene Andere präfiguriert die Erfahrung des Anderen im und als Anderen. Das Anderssein des Anderen reflektiert zugleich das am eigenen Leib erfahrene Anderssein meiner selbst. Der Andere erinnert in seiner Andersheit gewissermaßen an das Unverstandene, Nichteindeutige meiner selbst.

\section{Die leibhafte Erfahrung von Abhängigkeit, Endlichkeit und Sterblichkeit}

Die Differenzerfahrung in meiner eigenen Leiblichkeit und in dem, mit dem und durch das leiblich-soziale Gegenüber lässt sich in ihrem

19 Diese Aussage will nicht mit entwicklungspsychologischen Modellen zur Herausbildung von Selbst- und Fremdwahrnehmung konkurrieren, sondern darauf verweisen, dass der Referenzrahmen für das inhaltliche Verständnis zwischenmenschlicher Differenz einen materialen Ankerpunkt in der eigenen, leiblichen Differenzerfahrung hat. 
Erfahrungscharakter genauer bestimmen als Abhängigkeit, Endlichkeit und Sterblichkeit (Ringleben, 2002, S. 219): Ich erfahre mich als abhängig, insofern als ich mich in meiner Leiblichkeit nicht hervorbringe, sondern mich als vorgängig konstituiert und in einem immer schon auf mich Einfluss nehmenden (sozialen) relationalen Zusammenhang stehend vorfinde (Herms, 1991, S. 33-39). Ich erlebe mich endlich, insofern als meine Möglichkeiten und meine Fähigkeit, die geschöpfliche Wirklichkeit zu gestalten, begrenzt sind. Darin inbegriffen ist nicht nur die in Bezug auf unser Thema relevante Einsehbarkeit meiner sozialen Mitwelt in ihrer leiblichen Verfasstheit, sondern auch meiner selbst. Als Leib bleibe ich mir zeitlebens ein Rätsel. Zu dieser Einsicht führt auch das Selbsterleben als zeitliches, vergängliches Wesen. Leiblichkeit verweist in diesem Sinne darauf, dass mein Anfang und mein Ende aufgehoben sind in einer mir unverfügbaren, den immanenten WeltZusammenhang übersteigenden Wirklichkeit.

\section{Ein gelungenes Leibverhältnis}

Die Körpererfahrung, besonders die Begegnung mit dem unverstandenen leibhaften Anderssein meiner selbst in den unterschiedlichen Differenzerfahrungen, ermöglicht es mir und macht es nötig, mich zu meiner Leiblichkeit zu verhalten. Die medizinisch-technische Unterwerfung des leiblich Unverstandenen und Anderen sowie ein rein instrumentelles Verhältnis, in dem der Körper als handhabbares Ding betrachtet wird, können als Fehlverhältnisse zur eigenen Leiblichkeit verstanden werden. In einem sinnvollen Leibverhältnis weiche ich dem anders-seienden Leib nicht aus, sondern erkenne ihn an: Das ist der Fall bei der Bejabung meiner leiblich vermittelten letztlichen Andersheit und Unverfügbarkeit, die aber » vor dem Abweg der Naturvergötterung nicht geschützt « (Koch, 1978, S. 303) ist. Das ist auch der Fall für alle Versuche der Gestaltung des Leibes bis hin zur Körperbeherrschung. In dieser Perspektive läuft der Leib jedoch Gefahr, auf ein Medium zur Durchsetzung von Perfektibilitätsfantasien reduziert zu werden (ebd., S. 303). Als christliche Form des gelungenen Leibverhältnisses kommt schließlich die Aussöhnung mit dem mir leiblich begegnenden Anderssein meiner selbst in den Blick (ebd., S. 301-305) - das Auf-sich-Nehmen der eigenen Leibhaftigkeit 
(ebd., S. 305). Damit werden Gestaltungs- und Beherrschungsversuche nicht obsolet. Die Aussöhnung mit meiner Leiblichkeit, die Anerkennung meiner als leibhaft endliches, abhängiges und sterbliches Wesen bedeutet zunächst, einen realistischen Blick auf meine leibhafte Verfasstheit zu gewinnen. Alle Gestaltungsversuche werden so als in ihrer Wirkmächtigkeit begrenzte Versuche gewürdigt. Sie ermöglichen einen Umgang mit der Fragilität, Endlichkeit und Unverständlichkeit des Leibes, vermögen diese jedoch letztlich nicht zu überwinden.

Es besteht ein enger Zusammenhang zwischen dem Anerkennen der eigenen, leiblich erfahrenen Andersheit und der Anerkennung der Andersheit des Anderen. Diese Einsicht wird noch ausführlicher zur Sprache kommen.

\section{Exkurs: Das Geschlecht des Auferstehungsleibes}

Die leibhafte Erfahrung von Abhängigkeit, Endlichkeit und Sterblichkeit führt über die Frage nach dem Möglichkeitsgrund leiblicher Existenz auch zu der Hoffnung auf deren Überwindung und Ganzheit. Die in dieser Fragerichtung gewonnen Einsichten haben wiederum Einfluss auf die Beurteilung des irdischen Leibesverhältnisses und -umgangs.

In intensiver Auseinandersetzung mit der neutestamentlichen Exegese und deren Ergebnissen präpariert Ruth $\mathrm{Heß}$ das Geschlechterbild des Apostels Paulus aus dessen Gedanken zum Auferstehungsleib. ${ }^{20}$ Nach paulinischem Verständnis ist auch der geschlechtliche Körper Gegenstand des Vollendungsgeschehens. So gibt sich der Galaterbrief $3,28^{21}$ schon in seiner Form als » > eschatologische Antithese< zur pro-

20 Vgl. dazu auch Janssen (2001, 2005). Sehr aufschlussreich ist Heß' (2005, S. 294-302) Zusammenstellung der z.T. sehr unterschiedlichen, sich verändernden Versuche, die Frage der Geschlechtlichkeit des Auferstehungsleibes zu klären. Besprochen wird der Ansatz des Thomas-Evangeliums von Hieronymus, Aquinus, Schleiermacher und Barth. Besonders Schleiermacher zeichnet sich durch eine »programmatisch unbestimmte Schwebe« (S. 298) in dieser Frage aus, die ihm einen Umgang mit den Geschlechterkategorien jenseits von Beliebigkeit und Festgestelltheit ermöglicht.

21 »Hier ist nicht Jude noch Grieche, hier ist nicht Sklave noch Freier, hier ist nicht Mann noch Frau; denn ihr seid allesamt einer in Christus Jesus (Galaterbrief 3,28; diese und die folgenden Übersetzungen nach Luther [1984]). 
tologischen Fundierung der Geschlechterdifferenz innerhalb der ersten Schöpfungserzählung « (Heß, 2005, S. 310) zu erkennen. Von der eschatologischen, transformativen Vollendung der Schöpfung als Ganzer ist der Mensch in seiner Geschlechtlichkeit nicht ausgenommen. »Die Identität der neuen Kreatur weiß sich [...] in einen geistlichen Freiheitsraum hineingestellt, in dem das (geschlechtlich) Andere im Lichte des Kreuzes [...] fortan anders zur Geltung kommen kann - als entdualisiertes und antihierarchisches >Mit-ein-ander $<$ der Kinder Gottes $\ll$ (ebd., S. 312). Diesen negativen Bezug zur Geschlechtlichkeit (und der Ehe als sexuierter, d.h. vergeschlechtlichter Sozialform) unterstreicht auch das Markusevangelium 12,25 22 mit der Fokussierung eines Endes geschlechtlicher Fortpflanzung (ebd., S. 312).

Und auch dort, wo sie nicht explizit auf die Geschlechtlichkeit abheben, geben die paulinischen Aussagen doch Auskunft über das »Wie der eschatischen Transformation des Geschlechts(leibes), ihre[r] Richtung und Gestalt « (ebd., S. 313). So zeigt sich im 1. Korintherbrief 13,9-12 23 die eschatologische Vollendung als $\gg$ Aufdeckungs- und Klärungsereignis «, mit dem die diesseitige menschliche Selbsterkenntnis - zu der man wohl das Gewahrsein der eigenen Geschlechtlichkeit als Aspekt der Leiblichkeit wird dazurechnen müssen - zugleich unter den Vorbehalt der zukünftigen Vollendung gestellt wird (ebd., S. 314). Der 1. Johannesbrief 3,2 ${ }^{24}$ klärt die Spannung zwischen eschatologischer Transformation und Kontinuität in gleicher Weise, wenn gesagt wird, dass »die endzeitliche Verwandlung von Menschen [...] nicht

$22 »$ Wenn sie von den Toten auferstehen werden, so werden sie weder heiraten noch sich heiraten lassen, sondern sie sind wie die Engel im Himmel« (Markusevangelium 12,25).

23 »Denn unser Wissen ist Stückwerk, und unser prophetisches Reden ist Stückwerk. Wenn aber kommen wird das Vollkommene, so wird das Stückwerk aufhören. Als ich ein Kind war, da redete ich wie ein Kind und dachte wie ein Kind und war klug wie ein Kind; als ich aber ein Mann wurde, tat ich ab, was kindlich war. Wir sehen jetzt durch einen Spiegel ein dunkles Bild; dann aber von Angesicht zu Angesicht. Jetzt erkenn ich stückweise, dann aber werde ich erkennen, wie ich erkannt bin« (1. Korintherbrief 13,9-12).

24 »Meine Lieben, wir sind schon Gottes Kinder; es ist aber noch nicht offenbar geworden, was wir sein werden. Wir wissen aber: wenn es offenbar wird, werden wir ihm gleich sein; denn wir werden ihn sehen, wie er ist« (1. Johannesbrief $3,2)$. 
deren Identität [korrumpiert], sondern [...] vielmehr ihre vormals fragmentarische Gestalt allererst authentisch zur Geltung [bringt] (ebd., S. 315). Der 1. Korintherbrief 15,35-4925 schließlich antwortet auf die Frage, mit welchem Leib wir auferstehen werden. Die Passage hebt auf die leiblich vermittelte Kontinuität ab, betont aber mit der Unterscheidung von soma psychikon und soma pneumatikon zugleich die transformative Radikalität der neuschöpferischen (ebd., S. 317) Totenauferweckung (1. Korintherbrief 15,42-45): Die irdische Vielgestaltigkeit der (Geschlechts-)Leiber (1. Korintherbrief 15,38-41) geht über in die »eschatische Pluralität der Geschlechtsleiber und -identitäten $\ll$ (ebd., S. 316) (1. Korintherbrief 15,46-49).

\section{Zwischenfazit}

Gezeigt wurde: Die biologisch-medizinisch zu konstatierende faktische geschlechtliche Vielgestaltigkeit und Vieldeutigkeit kann theolo-

25 »Es könnte aber jemand fragen: Wie werden die Toten auferstehen, und mit was für einem Leib werden sie kommen? Du Narr: Was du säst, wird nicht lebendig, wenn es nicht stirbt. Und was du säst, ist ja nicht der Leib, der werden soll, sondern ein bloßes Korn, sei es von Weizen oder etwas anderem. Gott aber gibt ihm einen Leib, wie er will, einem jeden Samen seinen eigenen Leib. Nicht alles Fleisch ist das gleiche Fleisch, sondern ein anderes Fleisch haben die Menschen, ein anderes das Vieh, ein anderes die Vögel, ein anderes die Fische. Und es gibt himmlische Körper und irdische Körper; aber eine andere Herrlichkeit haben die himmlischen und eine andere die irdischen. Einen andern Glanz hat die Sonne, einen andern Glanz hat der Mond, einen andern Glanz haben die Sterne; denn ein Stern unterscheidet sich vom andern durch seinen Glanz. So auch die Auferstehung der Toten. Es wird gesät verweslich. Es wird gesät in Niedrigkeit und wird auferstehen in Herrlichkeit. Es wird gesät in Armseligkeit und wird auferstehen in Kraft. Es wird gesät ein natürlicher Leib und wird auferstehen ein geistlicher Leib. Gibt es einen natürlichen Leib, so gibt es auch einen geistlichen Leib. Wie geschrieben steht: Der erste Mensch, Adam, ıwurde zu einem lebendigen Wesen<, und der letzte Adam zum Geist, der lebendig macht. Aber der geistliche Leib ist nicht der erste sondern der natürliche; danach der geistliche. Der erste Mensch ist von der Erde und irdisch; der zweite Mensch ist vom Himmel. Wie der irdische ist, so sind auch die irdischen; und wie der himmlische ist, so sind auch die himmlischen. Und wie wir getragen haben das Bild des irdischen, so werden wir auch tragen das Bild des himmlischen« (1. Korintherbrief 15,35-49). 
gisch gewürdigt werden. Der Vorbehaltscharakter von Körperbildern und die letztliche Nichteindeutigkeit des Menschen erfahren in der christlich-theologischen Entfaltung der menschlich-leibhaften Existenzweise durchaus eine Begründung. Die letztliche Nichteindeutigkeit ist jedem Menschen in seiner leibhaften Grundverfassung eigen und kann nicht auf den Bereich des Geschlechtlichen beschränkt werden. Sie kann auch nicht auf den Bereich von Phänomenen geschlechtlicher Nichteindeutigkeit beschränkt werden, da das Unverstandene eben nicht an der Geschlechtlichkeit (als Körperbild oder einem Aspekt der Leiblichkeit) haftet, sondern an der Leiblichkeit als Ganzer bzw. als Grundstruktur der menschlichen Existenz. Diese Einsicht hat Folgen für grundlegende anthropologische Bestimmungen: Mehr als das jeweilige Geschlecht treten aus christlicher Sicht die konstitutive Relationalität und die individuelle, nicht binär-kategorisierbare Leiblichkeit in den Blickpunkt. Anders gesagt: Mit der aus dem christlichen Leibverständnis gewonnenen Flexibilität im Umgang mit menschlicher Geschlechtlichkeit für die Bestimmung von Identität kann Intersex als mögliches, individuelles Geschlecht anerkannt werden.

Der Leib ist das Medium, das den relationalen Weltbezug herstellt und in diesem Zusammenhang überhaupt erst menschliche Handlungsfähigkeit gewährleistet. Leiblich erfährt sich der Mensch als unverfügbar. Leiblich begegnet er sich selbst in seiner Widerständigkeit und Differenz. Leiblich ist der Mensch immer anders, als er sich sehen und annehmen kann - auch in seiner individuellen Geschlechtlichkeit. Das angemessene Verhältnis eines Menschen zu seiner Leiblichkeit kann als Aussöhnung bezeichnet werden. Aussöhnung beschreibt dabei ein Verhältnis jenseits bloßer Bejahung und Unterwerfung der eigenen und fremden leiblichen Andersheit; es verweist auf die leibliche und leiblich vermittelte Gestaltbarkeit und Beherrschbarkeit innerhalb des vorgegebenen (geschöpflichen) Möglichkeitsrahmens und widerspricht damit sowohl den Perfektibilitätsprogrammen als auch asketischer Leibverachtung. Christlich-theologisch kann die Leiblichkeit eingezeichnet werden in einen umfassenderen (heils-)geschichtlichen Horizont, durch den immer auch die Bedingung seiner Möglichkeit und die eschatologische Überwindung der leiblich vermittelten Beschränktheiten mit bedacht werden. 
Die Vehemenz, mit der die frühen Christ_innen die leibliche Auferstehung verteidigt haben, ist $\gg$ die entschiedene Betonung des ewigen Wertes, den die individuelle Person in ihrer Einmaligkeit darstellt. Die Individualität einer Person spricht sich in jeder Zelle ihres Leibes aus, vor allem in ihrem Antlitz « (Tillich, 1984, S. 466). Personsein, Individualität sowie deren Kontinuität durch den Tod hindurch haften jedoch nicht an einer bestimmten Körperzelle, an einem Leibausschnitt oder Körperbild. Sie stützen sich auf die leiblich erfahrene Gottesbeziehung. Der Begriff des Leibes umfasst als Totalbegriff die Gesamtheit meiner mir nicht verfügbaren, sondern gewährten konstitutiv relationalen Existenz. Nicht das Geschlecht, sondern der leiblich erfahrene Gottesbezug sichert das menschliche Personsein. ${ }^{26}$

\subsection{Eindeutigkeit zwischen geordneter und zu ordnender Schöpfung}

Die Deutung der grundlegenden menschlichen Existenzerfahrung mithilfe des Leibbegriffs ermöglichte die Diskussion der biologisch-medizinisch zu konstatierenden faktischen geschlechtlichen Nichteindeutigkeit bzw. Vieldeutigkeit.

Im vorangegangenen Kapitel ist bereits die theologische Diskussion der sozial kategorisierenden Rede von Mann und Frau, von Intersex, ferner von krank und gesund vorbereitet worden. Die kategorisierenden Bezugnahmen sind ein Versuch, meinen irdischen Leib und den des Anderen » zugänglich zu machen «. Die unterschiedlichen Betrachtungen von Leibesaspekten mittels Körperbegriffe dienen der ordnenden Gestaltung der menschlichen Grundrelationen (Selbst- und Weltver-

26 »Das Personsein [übersteigt] alle Besonderheiten und Veränderungen der Lebensumstände, weil es sich letztlich aus der Beziehung zu Gott als der Quelle seiner Integrität nährt. Darum kann es auch in aller individuellen Konkretion mit dem Menschsein schlechthin zusammenfallen, so daß die Begegnung mit anderen zum Anruf werden kann, in der Annahme der Besonderheit des eigenen Daseins selber Person zu sein: Die besonderen Lebensumstände und Verhältnisse zu anderen sind dann nicht mehr äußerliche und beliebig vertauschbare Rollen, sondern in ihnen prägt sich nun die Endgültigkeit des von Gott her begründeten Selbstseins in seinen Besonderheiten aus« (Pannenberg, 1991, S. 230). 
hältnis). Sie vermögen den Leib als Inbegriff aller Dimensionen meiner Existenz und auch aller Tiefengrade seiner Aspekte, jedoch nie vollständig, reflexiv einzuholen. Allein im Gottesverhältnis weiß der_die Glaubende sich so erkannt und erschlossen, wie er_sie ist (wie jedoch auch er_sie sich selbst nie ganz versteht). Das christliche Verständnis der körperlich-materialen Geschlechtlichkeit als Aspekt der menschlichen Leiblichkeit stellt dabei ein Korrektiv für den Umgang mit Geschlecht als sozialer Zuschreibung dar: Geschlechterkategorien müssen transparent im Hinblick darauf bleiben, was mit ihnen alles nicht erfasst ist.

Wie ist nun das Verhältnis von Eindeutigkeit und Nichteindeutigkeit zu bestimmen, das besonders in konstruktivistischen Überlegungen zur Geschlechtlichkeit zur Sprache kommt? Geschlecht rückt über die leibliche Selbsterfahrung hinaus auch als gesellschaftliche Ordnungskategorie in den Blickpunkt. Was leiblich eindeutig und nichteindeutig (Intersex) ist, hängt in entscheidender Weise davon ab, innerhalb welcher Ordnung die Leibesaspekte und damit auch Geschlecht erfahren und thematisch werden. Dieser Gedanke bedarf einer längeren Entfaltung.

\section{Soziale Wirklichkeit und Schöpfungsordnung}

Das Verhältnis von der ordnenden Gestaltung der Schöpfung durch den Menschen und der Beschaffenheit der Wirklichkeit als gestaltbarer und zu ordnender, ist das Thema des klassischen lutherischen Lehrstücks von der Schöpfungsordnung. In der Rede von der Schöpfungsordnung verbindet sich die Unterscheidung von Gesetz und Evangelium ${ }^{27}$ mit der Schöpfungsvorstellung ${ }^{28}$ : Nach christlichem Verständnis endet

27 Die hermeneutische Fundamentalunterscheidung von Gesetz und Evangelium differenziert das Wort Gottes in seine unbedingte Forderung an den Menschen (Gesetz) und seinen gnädigen, befreienden Zuspruch der Sündenvergebung (Evangelium).

28 Die Welt als Schöpfung zu sehen sagt nichts über die konkreten an der Entstehung von Welt und Wirklichkeit beteiligten Prozesse aus und bedeutet insofern nicht, Gott als alternative Erklärung zu naturwissenschaftlichen Kosmologien einzusetzen, sondern hebt vielmehr auf die Kontingenz der geschaffenen Wirklichkeit ab, ihre Nicht-Notwendigkeit - die Tatsache, »dass sie ihr Dasein nicht 
Gottes Schöpferwirken nicht im Akt der Hervorbringung der Welt ex nihilo; Gott wirkt auch in seiner Schöpfung als ihr Bewahrer, Beeinflusser und Lenker, weshalb Gottes erhaltendes Wirken auch als creatio continua (ta) bezeichnet wird. Im Zusammenhang dieses die geschaffene Welt durchwirkenden Schöpferhandelns wird der sogenannte usus politicus/civilis des Gesetzes plausibel: Das Gesetz, das sich auf den Schöpferwillen stützt, erfüllt seinen Zweck im Rahmen der Erhaltung der Schöpfungswerke, zu denen auch das Miteinander gehört. Neben seiner theologischen Aufgabe, den Sünder seiner Sündhaftigkeit zu überführen und für das Evangelium empfänglich zu machen (usus elenchticus), sichert das Gesetz in seiner Ordnungsfunktion das friedvolle menschliche Zusammenleben. Es verlangt in diesem Sinne vom Menschen nicht nur juridisch-politische Gesetzesbefolgung, sondern so müsste man konsequent weiterdenken - es sichert in Form von allgemein verbindlichen Konventionen, Regelmäßigkeiten der Interaktion usw. verlässliche Strukturen des Miteinanders. Insofern bewirkt das Gesetz lebensfördernde Eindeutigkeit in Gestalt von Regeln und Abläufen, die menschliches Miteinander zuallererst ermöglichen. ${ }^{29}$ Gleichwohl vermag dieses mit Gesetz bezeichnete Ordnungsbemühen nicht, den Menschen zu befreien; das geschieht erst in der gnädigen Zuwendung Gottes, die im Glauben erfahren wird. Das mit dem Gesetz legitimierte menschliche Ordnungsbemühen kann eine »Begrenzung und Eindämmung, [jedoch keine ...] wirksame Überwindung des Bösen durch das Gute « (Härle, 2007, S. 164) vollbringen. In diesem Verständnis ist das

sich selbst, sondern Gott verdankt« (Evers, 2010, S. 93f.). Das christliche Verständnis der geschaffenen Wirklichkeit als Schöpfung Gottes rechnet darüber hinaus mit einer noch ausstehenden, künftigen Erlösung des Gesamtzusammenhangs der endlichen Schöpfung durch ihren Schöpfer. Der dadurch aufgespannte (heils-)geschichtliche Horizont hat Konsequenzen für das Verständnis der Gegenwart: Die geschaffene Wirklichkeit »hat ihr Sein im Werden, sie ist offen für Neues, und es steht in ihr immer auch etwas auf dem Spiel« (ebd., S. 95).

29 Als Wirklichkeitsgestalt des Gesetzes versteht schon Luther u.a. die Obrigkeit. Wobei Luther weiß, dass die Obrigkeit nicht qua Existenz, unabhängig von ihrer konkreten Ausgestaltung als Gottes gute Schöpfungsordnung gelten kann. Obrigkeit hat nach Luther ihr Recht als christliche Obrigkeit. Vgl. dazu z. B. Luthers Äußerungen im Bauernkrieg, insbesondere die sogenannte Ermahnung zum Frieden auf die Zwölf Artikel der Bauernschaft. Diese Äußerungen können als Präzisierung der in der Obrigkeitsschrift dargelegten Zwei-Reiche-Lehre gelesen werden. 
Gesetz als Instrument zur heilsamen Wirklichkeitsgestaltung gewürdigt, jedoch unter den Vorbehalt des Evangeliums gestellt.

\title{
Die Einsehbarkeit und Gestaltbarkeit der geschaffenen Wirklichkeit
}

\begin{abstract}
$\gg \mathrm{Da}[\ldots]$ ein nach Regeln und Ordnungen differenziertes Mannigfaltiges wirklich ist und nicht Nichts oder nur Chaotisches, daß dieses so wirklich ist, wie es ist, und daß es sich innerhalb dieser verläßlichen Regeln und Ordnungen so vollzieht, daß es immer neue und vielfältige Gestalten hervorbringt, ist in der Souveränität und Treue des Schöpfers begründet « (Evers, 2000, S. 857).
\end{abstract}

Alles Seiende partizipiert an Gott als dem Seinsgrund, der über Sein und Nicht-Sein entscheidet (Tillich, 1956, S. 276). Und als Grund des Seins ist Gott auch »Grund der Struktur des Seins. Er ist dieser Struktur nicht unterworfen, die Struktur ist in ihm gegründet « (ebd.). In ihrer Verwirklichung (Aktualisierung) gewinnt die geschaffene Wirklichkeit in jedem konkreten Seienden Form und als Gefüge der Gesamtheit alles konkret Seienden Regelmäßigkeit - eine strukturierte Ordnung. Erst diese Ordnung der geschaffenen Welt in ihrer Bedingtheit, in der Formgebung ihrer Elemente und in der Regelmäßigkeit ihrer Interaktionen ermöglicht die Ausbildung und Entfaltung von Leben, auch von sozialem Leben. Das Gefüge dieser Bedingungen, denen die menschliche Existenz unterliegt, die ihrerseits zugleich die Bedingung der Möglichkeit menschlicher Handlungsfähigkeit im Rahmen der in allen Dimensionen relational verfassten geschaffenen Wirklichkeit gewährleistet, versteht Herms als Schöpfungsordnung (Herms, 1992, S. 444-448).

Die Struktur der geschaffenen Wirklichkeit ist auch die Bedingung der Möglichkeit ihrer Intelligibilität. ${ }^{30}$ Die Einsehbarkeit der struktu-

30 Die in der Auseinandersetzung mit dem Platonismus gewonnene theologische Denkfigur der Inkarnation des göttlichen Logos in Jesus Christus verweist darauf, »daß die rationale und kommunikative Struktur, die der Grund der Erkennbarkeit der Welt ist, in der raum-zeitlich verfaßten geschichtlichen Welt zur Erscheinung kommt und erfahrbar wird (Schwöbel, 2002, S. 154). 
rierten, aus Glaubensperspektive als Schöpfung erfahrenen Wirklichkeit besagt jedoch nicht, dass unsere ordnenden Bezugnahmen den Wirklichkeitszusammenhang im Sinne eines Abbildungsverhältnisses adäquat erfassen. ${ }^{31}$ Die göttliche Schöpfungsordnung geht in keinem menschlichen Entwurf der Beschaffenheit der Wirklichkeit auf.

\section{Gestaltung sozialer Ordnung als »Praxissituation endlicher Freiheit«}

Die Lehre von der Schöpfungsordnung erschließt in diesem Sinne »die Wahrheit über die Existenz der Menschen: über ihren Charakter als einer Zumutung und Verheißung; dadurch ermöglicht sie dem Glauben, den Zumutungscharakter seiner im Werden befindlichen Handlungsgegenwart im Lichte ihres Verheißungscharakters zu verstehen « (Herms, 2004, S. 990). Der Mensch kann die geschaffene Welt nicht nur gestalten, er ist immer schon als ein sie Gestaltender in sie eingebunden. Herms spricht deshalb davon, dass die Schöpfungsordnung als Bedingungsgefüge endlicher Freiheit zugleich den $\gg$ Inbegriff von gleichursprünglichen Grundanforderungen oder Grundproblemen [...] für die interaktionelle Praxis endlicher Freiheit « (Herms, 1992, S. 448) darstellt. Herms identifiziert mehrere unterscheidbare, aber eng miteinander verwobene und aufeinander bezogene Gestaltungsbereiche ${ }^{32}$, die aus den Grundbedingungen der geschaffenen Wirklichkeit (Schöpfungsordnung) erwachsen. Die $Z u$ schreibungen von Geschlecht, wie sie uns traditionell z.B. in bipolaren Geschlechtermodellen als Geschlechterkategorien begegnen, erschei-

31 Die Frage nach der Erkenntnisbeziehung zwischen der Wirklichkeit und unserer Bezugnahme auf Wirklichkeit soll an dieser Stelle nicht vertieft werden. Es sei nochmals darauf verwiesen, dass - in dem hier vorausgesetzten Verständnis - unsere Entwürfe von Wirklichkeit zuallererst durch deren Widerständigkeit ihren Realismus erhalten, es also keine direkte menschliche Bezugnahme auf das Ganze von Wirklichkeit gibt, der Letzterschließungskraft innewohnen würde (Evers, 2014).

32 Sicherung des »Stoffwechsels«(Wirtschaft), Sicherung der Einhaltung von Interaktionsregeln (Herrschaft), Gewinnung von technisch orientierendem Wissen (Wissenschaft), Gewinnung von ethisch orientierendem Wissen (Religion/Weltanschauung). Vgl. z. B. Herms (1992, S. 448ff.). 
nen vor diesem Hintergrund als begriffliche Versuche, das Miteinander in seinen verschiedenen, ineinandergreifenden Gestaltungsbereichen $\mathrm{zu}$ ordnen und zu gestalten. ${ }^{33}$ Als grundlegende Gestaltungskategorien, die in allen gesellschaftlichen Bereichen zum Tragen kommen, werden sie stabilisiert und unsichtbar gemacht. ${ }^{34}$ Das kann jedoch bei genauer Betrachtung nicht darüber hinwegtäuschen, dass es sich auch bei dem entwickelten kategorialen Zugriff auf die gestaltbare und zu gestaltende, geschaffene Wirklichkeit um menschliche Hervorbringungen handelt. Ein solches Verständnis impliziert, dass diese Hervorbringungen nicht in einem Adäquanzverhältnis zur Wirklichkeit an sich stehen. Sie können es nicht, weil sie - obwohl von Gott in ihrem ordnungs- und klarheitsstiftenden Anliegen gewollt - das Produkt von geschöpflichem Ordnungsbemühen bleiben, das immer nur annäherungsweise in Kongruenz mit der im Schöpferwillen gründenden geordneten Wirklichkeit als Ganzer zu bringen ist. Abzulehnen sind deshalb

» alle Gestalten der Lehre [von der Schöpfungsordnung], die [...] statt der Aufgabe einer der Selbsterhaltung und dem Erhaltungswillen des Schöpfers entsprechenden Ordnung [...] des Zusammenlebens bestimmte gesch [ichtlich] gewordene Lösungen dieser Aufgabe als zur von Gott stammenden Ordnung der Schöpfung zählen, sei es als positive Ordnungen $[\ldots]$ oder als Not- und Erhaltungsordnungen $[\ldots] \ll$ (Herms, 2004, S. 991).

33 So weit geht Herms nicht. Im Gegenteil: Die Interpretationsräume, die sein Verständnis der Schöpfungsordnung eröffnet, lässt Herms in Bezug auf Geschlecht und die vergeschlechtlichten Sozialgestalten des Zusammenlebens (z.B. die heterosexuelle Ehe) ungenutzt bzw. fällt dahinter zurück, so etwa in seinem Aufsatz »Liebe, Sexualität, Ehe« (2007): »D[er] grundlegende und unüberholbare Charakter der Geschlechterdifferenz wird keineswegs durch das Auftreten von Hermaphroditen infrage gestellt [...] (Herms, 2007, S. 410). In diesem Sinne ist auch das auf Reproduktionszwecke enggeführte Eheverständnis zu begreifen: »Die Ehe ist ein in allen Gesellschaften anzutreffendes Rechtsinstitut zum Schutze der Elternschaft und der Erziehungsgemeinschaft« (ebd., S. 415). Gänzlich unverständlich erscheint die biologistisch anmutende Erklärung des »Wohlgefallens am anderen « im Rahmen der Reproduktion der Gattung (ebd., S. 413f.).

34 Zur sozialen Herstellung von Geschlecht vgl. u. a. Karle (2006, S. 35-80), Goffman (1994) oder Lorber (1999, insbes. S. 55-190). 
Geschlechterkategorien als aller Verhandelbarkeit entzogene anthropologische Transzendentalien zu verstehen hieße, sie mit der Schöpfungsordnung zu identifizieren.

Menschliche Ordnungsentwürfe können in ihrem konstruktiven Charakter als Lesbarmachen der geordneten Schöpfung verstanden werden. Geschlechterkategorien stellen einen solchen Intelligibilisierungsversuch dar, indem sie eine Auswahl von biologisch zugänglichen Merkmalen einfangen und kategorial zusammenbinden. ${ }^{35}$ Problematisch ist nicht die Herstellung von Intelligibilität, sondern die damit verbundene »Politik der Wahrheit« (Foucault, 2012; zit. n. Butler, 2009, S. 97), die unterschlägt, dass die Kategoriengestalt nur einen möglichen Ordnungsversuch darstellt, der sich an der Wirklichkeit bewähren muss, d.h., dass er auch an ihr scheitern kann (Evers, 2014). Nichts anderes besagt die Rede von der Entsprechung der eigenen Lebens- und Umweltgestaltung und dem Schöpferwillen. Eine Beurteilung der Geschlechterkategorien als konkreter Ordnungsgestalt muss dementsprechend aus der Frage erwachsen: »Was kann ich in Anbetracht der gegenwärtigen Seinsordnung sein? « (Butler, 2009, S. 98). Oder anders: Ist die Ordnung lebensdienlich oder beschränkt sie, allein um des Festhaltens an der Ordnungsgestalt willen, Entfaltungsmöglichkeiten?

\section{Geschlecht und Schöpfungsordnung}

Die Notwendigkeit, mein leiblich vermitteltes Welt- und Selbstverhältnis zu gestalten, bringt Geschlecht als kategorisierende Zuschreibung hervor. Der Umgang mit Geschlechterkategorien unterliegt dabei der

»Aufgabe der Ausbildung einer Ordnung des Zusammenlebens, die alle für die Erhaltung der Gattung im Naturprozeß erforderlichen Leistungen [...] erbringt und gleichzeitig dem Ziel des göttlichen Erhaltungshandelns - eben der Erkenntnis der vom Schöpfer selbst gestellten

35 Benennung ist nicht Beschreibung: »Der Name ordnet eine Auswahl frei flottierender Signifikanten zu einer >ldentitätı, stiftet mit ihnen ıldentität<; der Name >vernäht` auf wirkungsvolle Weise das Objekt« (Žižek, zit. n. Butler, 1995, S. 286). 
Grundaufgabe und der Befreiung zu ihrer Wahrnehmung - entspricht und dienlich (also: bildungskräftig) ist « (Herms, 2004, S. 991).

Die sich aus diesem Gedanken ergebende ethische Arbeit muss im Detail an anderer Stelle fortgesetzt werden. Fest steht: Die Ordnung hat nicht um der Ordnung willen ihr Recht, sondern um der Freiheitsräume willen, die als Gestaltungsmöglichkeiten durch sie erschlossen werden. Allein die Lebensdienlichkeit entscheidet über die Angemessenheit der kategorisierenden und die geschaffene Wirklichkeit gestaltbar machenden Benennungen, als die auch Geschlechterkategorien verstanden werden können.

\section{Exkurs: Die Schöpfung des Menschen}

Als biblischer Schlüsseltext für das Verständnis von Geschlecht gilt gemeinhin der erste sogenannte Schöpfungsbericht, besonders die Verse Genesis 1,26-29:

»Und Gott schuf den Menschen zu seinem Bilde, zum Bilde Gottes schuf er ihn; und schuf sie als Mann und Frau. Und Gott segnete sie und sprach zu ihnen: Seid fruchtbar und mehret euch und füllet die Erde und machet sie euch untertan $[\ldots] . \ll$

Menschliche Geschlechtlichkeit erscheint hier als Ausfaltung des Ebenbildes Gottes in den Raum des Geschaffenen hinein in Form zweier komplementär-geschlechtlicher Hälften. Aus diesem Verständnis eine Idealkonfiguration für die menschliche Geschlechtlichkeit und die Gestaltung menschlicher Beziehungen abzuleiten, scheint aus Perspektive der heutigen Exegese jedoch wenig plausibel. Zunächst ist darauf zu verweisen, dass es sich bei den Schöpfungsberichten ihrer Gattung nach um Ätiologien handelt: Narrativ wird eine Erfahrungswahrheit aus einem Ereignis der Vergangenheit begründet. Der Anspruch der Texte ist es, die vorzufindende Wirklichkeit aus ihrem Gewordensein heraus zu erklären, nicht jedoch, eine normative Geschlechtertheorie zu entwerfen. Allein diese Absicht zu unterstellen scheint angesichts des Entstehungskontextes geradezu anachronistisch. 
Die Gottebenbildlichkeitsvorstellung hat ihren Ursprung in der altorientalischen Königsideologie. Der Herrscher ist als Bild Gottes dessen Vergegenwärtigung in der Welt. Das Bild Gottes, wie auch das Bild des Herrschers, ist zudem nicht nur Repräsentation; es ermöglicht Kommunikation. »Bild Gottes zu sein, meint keine Entsprechung in Aussehen und Gestalt, sondern in der Funktion. Der Mensch wird dementsprechend auch nicht nach dem Bilde Gottes, sondern zum Bild Gottes geschaffen « (Karle, 2006, S. 219; Schüle, 2005). Die lebensnotwendige Aufgabe, die Schöpfung zu gestalten und zu beherrschen, wird hier mit einem Anspruch versehen, der aber eher auf den Umgang des Menschen mit der geschaffenen und zu gestaltenden Umwelt abzielt, als auf das Verhältnis der Geschlechter. Dementsprechend sind Imago Dei und Dominium Terrae die eigentlich aufeinander bezogenen und zu beziehenden Glieder des Textabschnitts. Die Übertragung der Gottebenbildlichkeit auf jeden Menschen ist eine geistesgeschichtliche Revolution: Der_die Einzelne wird in ein unmittelbares Gottesverhältnis gehoben. Die Gottebenbildlichkeit konkretisiert sich in einem bestimmten Umgang mit der Schöpfung. Weder eine Geschlechterhierarchie noch eine exklusive zweigeschlechtliche Matrix lassen sich jedoch daraus begründen.

Interessanter noch in Bezug auf unsere Fragestellung ist die sogenannte Paradiesgeschichte, der zweite Schöpfungsbericht, an den sich die Geschichte des sogenannten Sündenfalls anschließt. Gott will den geschlechtlich noch undifferenzierten adam aus seiner Einsamkeit befreien. In seiner Suche nach einem dem Menschen angemessenen Gegenüber erschafft er das gesamte Tierreich, bis er schließlich ischah aus Erde (adamah) und der Rippe des adam gewinnt. Einzelne Exegeten sehen in Anschluss an eine jüdische Auslegungstradition in adam ein androgynes Wesen (Gross, 1999); erst mit der Erschaffung der Frau sei vom Menschen in seiner Differenziertheit (als ischah und isch) die Rede. ${ }^{36}$ Auffallend ist die zentrale Stellung des Menschen in dem Schaffensakt: Auch wenn der Schöpfungsbericht wohl nicht mit einem

36 Gegen eine solche Interpretation spricht, dass die Paradieserzählung die Terminologie adam (nicht isch) und ischah konsequent durchhält: Adam ist also sowohl der erste Mensch als auch der erste Mann. Ein androgynes Vorwesen gibt es wohl nicht. Auch hier gilt, dass die Unterstellung von Geschlechtersensibilität an dieser Stelle - nach christlich-westlich-universitär-theologischen Maßstäben - eher anachronistische Exegese ist. 
$\gg$ non-gendered « Körperkonzept arbeitet, ${ }^{37}$ wird die Frau erst zur Frau durch die Benennung durch adam (Karle, 2006, S. 212-217): »Das ist doch Bein von meinem Bein und Fleisch von meinem Fleisch; man wird sie Männin nennen, weil sie vom Manne genommen ist « (Gen 2,23). Nach den Versuchen, dem Menschen ein angemessenes Gegenüber zu erschaffen, beendet der Mensch den göttlichen Schöpfungsakt mit der Benennung. In der Namensgebung stellt er zugleich fest, dass ihm kein Tier ein gleichwertiges Gegenüber sein kann. Benennung und Entsprechung gelingt ihm schließlich bei der Frau. Erst die Benennung jedoch macht das Gegenüber zu einem erkennbaren, lesbaren - gleichwertigen Gegenüber.

Es bleibt die Frage, was der eigentliche Skopus der Ätiologie ist, wenn es die normative Begründung einer bestimmten Geschlechterkonfiguration nicht sein kann. Ein zweiter Blick auf den Text offenbart, dass die Einsamkeit des ersten Menschen als eigentliches Defizit identifiziert wird. Der Mensch bedarf eines ihm entsprechenden, gleichwertigen Gegenübers. Kein Tier kann dieser Aufgabe gerecht werden, weshalb das Schöpfungswerk mit der Erschaffung der Tierwelt noch nicht vollendet ist. Es geht also um die ätiologische Begründung, warum und dass der Mensch konstitutiv ein Beziehungswesen ist. ${ }^{38}$

Auch dass die reproduktive Sexualität nur ein Aspekt der Geschlechtlichkeit ist, wird schon im biblischen Schöpfungsbericht erkannt. Genesis 2,24 bezieht die Geschlechtlichkeit nicht unmittelbar auf die menschliche Vermehrung (Karle, 2006, S. 212), diese taucht erst als Ergebnis des Falls auf. Damit ist die Fortpflanzungsfähigkeit als menschliche Möglichkeit nicht diskreditiert. Sie als Bestimmung des Menschen überhaupt aus den Schöpfungsberichten zu entwickeln, ist jedoch angesichts dieser Quellengrundlage nicht ohne Weiteres möglich.

37 So Karle (2006, S. 213).

38 Otto (1996) u.a. lesen den zweiten Schöpfungsbericht in diesem Zusammenhang gar als Korrektur des ersten Berichts und betrachten ihn nicht nur in Ausschnitten als Text der altisraelitischen Weisheitstradition. Was das Konzept von der Gottebenbildlichkeit und der damit formulierten Übertragung der königlichen Würde auf einen jeden Menschen nicht zum Ausdruck bringt, ist die grundlegende menschliche Sozialität und Beziehungshaftigkeit. Gen 2-3 hebt darauf ab und korrigiert die auch innerbiblisch umstrittene Vorstellung der Gottebenbildlichkeit (Karle, 2006, S. 217-223, die sich vor allem auf Schüle [2005] bezieht). 


\section{Zwischenfazit}

Geschlechterkategorien stellen sich in theologischer Perspektive flexibel dar. Dem konstruktivistischen Verständnis von der sozialen Herstellungvon Geschlecht ist aus theologischer Perspektive nicht per se zu widersprechen.

Geschlechtliche Eindeutigkeit und Nichteindeutigkeit tauchen im Rahmen bestimmter sozialer Ordnungsgestalten auf, die immer das Ergebnis menschlicher Intelligibilisierungs- und Sinngebungsversuche sind, in ihrer konkreten Ausgestaltung jedoch nie die Materialisierung des Schöpferwillens. Menschliche Ordnungen, die in der Gestaltbarkeit der geschaffenen Wirklichkeit begründet sind, erschließen Lebensmöglichkeiten. Von der Möglichkeit zu irren nicht frei, können sie in der Verwechslung menschlicher Ordnungsgestalten mit der göttlichen Schöpfungsordnung auch Lebensmöglichkeiten einschränken. Für menschliche Ordnungen, in denen von geschlechtlicher (Nicht-)Eindeutigkeit die Rede ist, gilt: Sie erfassen nicht die geschlechtliche Wirklichkeit an sich. Die anthropologischen Totalisierungen von bestimmten Geschlechterkonfigurationen, mit deren Hilfe das geschlechtlich Nichteindeutige aus dem intelligiblen Bereich verbannt wird, sind deshalb nicht haltbar.

Im pathologisierenden Umgang mit Intersexen verbinden sich ein falsches Leibverhältnis und ein Missverständnis der Schöpfungsordnung. Anstatt Lebensmöglichkeiten zu erschließen, werden Lebensmöglichkeiten genommen. Dahinter steht ein Mechanismus, der nicht nur auf der Vergötzung einer totalisierten menschlichen Ordnung beruht, sondern auch auf der Konstituierung eines Außen-Bereichs. Was dazugehört, muss in dieser Logik ausgeschlossen werden. Das Körperliche bietet sich als Bereich an, in dem über das konstitutive Außen, d.h. das Nicht-Typische und damit Nicht-Menschliche, entschieden wird. Dieser Gedanke soll unter Aufnahme der bisherigen Ergebnisse im Folgenden weiterentwickelt werden.

\subsection{Geschlechtliche Nichteindeutigkeit und Zwang zur Eindeutigkeit}

Ein Verständnis von Geschlecht als kategorialer Hervorbringung im Rahmen menschlicher Intelligibilisierungsversuche öffnet den Blick 
für das »konstitutive Außen « (Butler, 1995, S. 267) der entwickelten Geschlechtermatrix als strukturierender Seinsordnung. Jeder Benennungs- und Definitionsakt impliziert einen Akt ausschließender Feststellung. Die Unterscheidung von »innen «, also als menschlich normal-geschlechtlich identifizierbar, und » außen «, im Sinne aller nichtlesbaren Geschlechter, verliert in dieser Perspektive den in der Naturalisierung gewonnenen Absolutheitscharakter und wird verhandelbar. Die Alternative zu solch einer falschen essenzialistischen, identitären Feststellung von Geschlecht ist nicht Willkür und Beliebigkeit. Es stellt sich vielmehr die Frage, mit welcher Notwendigkeit und in welcher Zwangsläufigkeit jemand als Auszuschließende_r erscheint.

Der im Rahmen einer bestimmten Geschlechtergrammatik nichteindeutige Mensch ist aufgrund seines So-seins immer wieder schlimmsten Demütigungen und Todesgefahren ausgesetzt gewesen. Das Andere, Nicht-Lesbare, Abnorme wurde auch als Infragestellungund Gefährdung des sozialen Gefüges erlebt und verstoßen. Der Grat zwischen dem Eindeutigkeit suchenden Entwurf, der Leben und Gestaltung ermöglicht, und dem Zwang, vermeintliche Eindeutigkeit gegen das Nichteindeutige durchzusetzen, ist schmal. Diese Spannung und ein Umgang damit, der sich aus theologischer Perspektive nahelegt, sollen abschließend vor dem Hintergrund geschlechtlicher Nichteindeutigkeit zur Sprache gebracht werden.

In Anlehnung an René Girards Theorie des mimetischen Begehrens lässt sich der Ausschluss, die Abgrenzung des Außen einer jeden Ordnung, auch als Sündenbockmechanismus ${ }^{39}$ verstehen. Der Nächste ist immer auch

»Träger eines Begehrens [...], das die >Dimension der unendlichen Dinge $<$ hat, aber wir nehmen nicht wahr, was dieses Unendliche verbirgt:

39 Girard erkennt hinter den Ausgrenzungsphänomenen einen immer gleichen archaischen, sozial-hygienischen Mechanismus: »Weil unsere Begehren mimetisch [d.h. nachahmend] sind, gleichen sie sich und treten zu hartnäckigen, sterilen und ansteckenden Oppositionssystemen zusammen. Das sind Ärgernisse. Sie vervielfachen und bündeln sich und stürzen die Gemeinschaften in eskalierende Krisen, die ihren Höhepunkt erreichen, wenn die einmütige Polarisierung gegen ein einziges und alleiniges Opfer das allgemeine Ärgernis hervorbringt, den ^Fixationsabszeß«, der die Gewalt besänftigt und das zerfallene Ganze wiederherstellt« (2008, S. 124). 
die Vergötzung des Nächsten, zwangsläufig gepaart mit der eigenen Vergötzung und dennoch mit dieser schlecht vereinbar. Die Hauptquelle der menschlichen Gewalt sind die aus unserer doppelten Vergötzung resultierenden unlösbaren Verstrickungen « (Girard, 2008, S. 26),

die immer in einer exzessiv-gewaltsamen Entladung kulminieren. Geschlechtlich nichteindeutige Menschen sind danach lediglich ein sozialhygienisch geeignetes Ventil - das erstbeste Opfer neben möglichen anderen Außenseiter_innen - für eine gewaltsame und nach Befriedung lechzende Mehrheitsgesellschaft. Der kollektive Exzess von Gewalt an einem willkürlichen Opfer ermöglicht die »Verwandlung des Alle-gegen-Alle, das die Gemeinschaft fragmentiert, in ein Alle-gegen-Einen, das sie versammelt und eint « (Girard, 2008, S. 38). Warum aber richtet sich die Gewalt ausgerechnet gegen das geschlechtlich »Abnorme «, das durch seine reine Existenz doch leicht als gottgewollt verstanden werden könnte? Wie wird das körperlich Nichteindeutige zum erstbesten Opfer?

\section{Exkurs: Hermaphroditismus zwischen Verehrung und Dämonisierung}

In Anknüpfung an die jüdisch-rabbinische Exegese des zweiten Schöpfungsberichts versteht die Alchemie Adam als geschlechtlich undifferenziertes, vollkommenes Vorwesen. Für die Herstellung von Gold bedarf der Alchemist nun des sogenannten Steins der Weisen, eines Symbols für die aristotelische materia prima bzw. für die Erde, aus der Adam gemacht ist - »Stein und doch kein Stein, gleichzeitig männlich und weiblich, daher Hermaphrodit genannt « (Grasshoff, 1617, Der kleine Bauer; zit. n. Neuer Berliner Kunstverein, 1986, S. 62 $)^{40}$.

Die Vorstellung vom Hermaphroditen als Verkörperung von Vollkommenheit liegt auch verschiedenen Heiligendarstellungen zugrunde. Nicht nur eine androgyne, vorpubertär-kindhafte Weichzeichnung von Gesichtszügen und Habitus soll dabei die Heiligkeit unterstreichen. Die

40 Zum Hermaphroditen als Symbol in der Alchemie vgl. Neuer Berliner Kunstverein, 1986, S. 57-74. 
Darstellungen der Heiligen Kümmernis (Sancta Wilgefortis) in Wort und Bild spielen mit den physischen Geschlechtermerkmalen: Gegen ihre Verheiratung mit einem Heiden wehrte sich eine junge Christin mit der Gebets-Bitte um körperliche Verunstaltung. Sie wurde erfüllt, und der jungen Frau wuchs ein Bart. Zur Strafe ließ der Vater seine Tochter ans Kreuz schlagen. In seiner gekreuzigten, bärtigen Tochter erkannte er den leibhaftigen Christus und bekehrte schließlich sich und sein ganzes Haus. Die Physiognomie der Gekreuzigten unterscheidet sich in künstlerischen Darstellungen der Heiligen Kümmernis nicht von derjenigen der Christusdarstellungen.

Der Teufel ist in der christlichen Ikonografie nicht nur mit tierischen und menschlichen Körperteilen ausgestattet; er besitzt auch unterschiedliche Geschlechtsmerkmale. Meines Erachtens stützt sich die Darstellung nicht nur auf den Glauben, »daß eine Mißgestalt Gottesstrafe sei « (Neuer Berliner Kunstverein, 1986, S. 43). Die gemischt-geschlechtliche bzw. geschlechtlich uneindeutige Darstellung des Teufels beruht ebenso auf der gerade skizzierten Vorstellung von Vollkommenheit, die sich nach einem bestimmten Verständnis der biblischen Darstellung der Erschaffung von Mann und Frau aus Adam auch körperlich niederschlagen muss. Der Satan als Verwirrer, der Vollkommenheit, Ganzheit, Allmacht vorgaukelt, tarnt sich als körperlich vollkommenes, d. h. nicht » geschlechtlich differenziertes und fragmentiertes « Wesen.

\section{Bedroht durch das Andere (in mir)}

Der ikonografische Exkurs legt die Vermutung nahe: Die Wahrnehmung von Intersexen wurzelt immer auch in einem Zerrbild von ersehnter, aber unerreichbarer Vollkommenheit. Was nicht eindeutig männlich oder weiblich ist, was sogar Merkmale beider Geschlechter trägt, verweist in seiner Vieldeutigkeit auch auf ein Mehr an (sexuellen) Möglichkeiten, das der Mehrzahl der nach konventionellen Kriterien geschlechtlich eindeutigen Menschen versagt bleibt. Die Projektion einer Vorstellung von Vollkommenheit führt zur Verdammung derjenigen Menschen, die als leibhaftige Materialisierungen dieser Vollkommenheitsvorstellungen angesehen werden. 
Der Gedanke einer Begegnung mit einem vermeintlichen Mehr an Lebensmöglichkeiten in dem Anderen lässt sich unter Berücksichtigung des zum leibhaften Selbsterleben bereits Gesagten auch in eine weitere Richtung ausdehnen. In der Begegnung mit dem geschlechtlich Nichteindeutigen und doch Lebensfähigen offenbart sich die Willkür der geltenden geschlechtlich-körperlichen Intelligibilitätsordnung. Fraglich wird damit zugleich der Rahmen, in dem sich das eigene körperlich-geschlechtliche Selbstverstehen bewegt. Die Überschreitung von Eindeutigkeitsgrenzen und die Offenbarung der Begrenztheit der selbstverständlichen Identitätskategorien werden immer auch als existenzielle Bedrohung empfunden.

Elizabeth Grosz spricht von »freak« und fokussiert damit die grundstürzende, alles Selbstverständliche infrage stellende Erfahrungsqualität, die die Begegnung mit dem unverständlichen Anderen annehmen kann:

»The freak is an object of simultaneous horror and fascination because, in addition to whatever infirmities or abilities he or she exhibits, the freak is an ambiguous being whose existence imperils categories and oppositions dominant in social life. [...] Freaks cross the borders that divide the subject from all ambiguities, interconnections, and reciprocal classifications, outside of or beyond the human. They imperil the very definitions we rely on to classify humans, identities, and sexes - our most fundamental categories of self-definition and boundaries dividing self from otherness « (Grosz, 1996, S. 57).

Die Grenzüberschreitung lässt ein sich in den sozial-kategorialen Grenzen vollziehendes Leben nicht als Zwangsläufigkeit, sondern als Möglichkeit erscheinen. Deshalb verweist die Angst, die die Begegnung mit dem Nichteindeutigen prägt, auch auf die Angst, dem Unverstandenen, Mehrdeutigen in uns zu begegnen. Das nichteindeutige Andere zu unterdrücken ist immer auch ein Versuch, all das Nichteindeutige, Unverstandene, Noch-Mögliche und damit zum Handeln und zur Veränderung Nötigende in uns, zu unterdrücken.

»The perverse pleasure of voyeurism and identification is counterbalanced by horror at the blurring of identities (sexual, corporeal, personal) 
that witness our chaotic and insecure identities. Freaks traverse the very boundaries that secure the $>$ normal< subject in its given identity and sexuality «,

stellt Grosz fest und ergänzt den religiös-ikonografischen Abriss mit ihrem Verweis auf die Profanliteratur:

»Monsters involve all kinds of doubling of the human form, a duplication of the body or some of its parts. The major terata recognized throughout history are largely monsters of excess, with two or more heads, bodies, or limbs, or with duplicated sexual organs « (ebd., S. 64).

Die Möglichkeit zur Veränderung bedeutet Infragestellung, und sich ihr auszusetzen, erfordert Anstrengung. Sich dagegen zu wehren bzw. » die Grenzen dessen zu verstärken, was als real angesehen wird, verlangt das Abwürgen von allem, was kontingent ist, offen ist für eine grundlegende Veränderung in der geschlechtlich festgeschriebenen Ordnung der Dinge « (Butler, 2009, S. 62).

\section{Menschliche Eindeutigkeiten und ihr Scheitern am Kreuz}

»Die Person, die Gewalt androht, geht von der angstvollen und starren Überzeugung aus, dass ein Weltverständnis und ein Selbstverständnis radikal untergraben wird, wenn einem [...] nicht kategorisierbaren Wesen erlaubt wird, in der sozialen Welt zu leben. Die Negierung dieses Körpers durch Gewalt ist ein vergeblicher und gewaltsamer Versuch, die Ordnung wiederherzustellen, die soziale Welt auf der Grundlage eines intelligiblen Geschlechts zu erneuern und die Herausforderung abzuwehren, sich diese Welt als etwas zu denken, was anders als natürlich und notwendig ist « (Butler, 2009, S. 61).

Eindeutigkeit ist relative Eindeutigkeit, die sich erst aus einer bestimmten Ordnung heraus ergibt. Keine menschliche Ordnung vermagjedoch, die geschaffene Welt abbildhaft darzustellen. Ein auf letzte Eindeutigkeit und Dauerhaftigkeit festgelegtes (Miss-)Verständnis der eigenen 
Leiblichkeit und der Schöpfungsordnung wird am stärksten in dem Ereigniszusammenhang infrage gestellt, den das Christentum in Kreuz und Auferstehung symbolisiert. Angezweifelt wird damit in unübertroffener Deutlichkeit auch der pathologisierende Umgang mit Intersex.

Kreuz und Auferstehung entlarven das zwanghafte Begehren des Menschen nach vollkommener Ordnung und Eindeutigkeit als todbringend. Der verurteilte Gotteslästerer und Sozialrevolutionär Jesus kann nach menschlicher Logik nicht der Messias sein. Am Kreuz scheitern selbst Jesu engste Vertraute. ${ }^{41}$ Indem sich Gott in Jesus zu erkennen gibt und in ihm den Tod überwindet, zerschellt am Kreuzestod jede Eindeutigkeits-Logik und lässt den Menschen sich seiner konstitutiven Nichteindeutigkeit und letztlichen Nichterschlossenheit gewahr werden. Damit wird das Nichteindeutige von dem ontologischen Missverständnis befreit und der Ball gewissermaßen an die menschliche Erkenntnisfähigkeit zurückgespielt. Eindeutigkeiten bleiben geschöpfliche, also vorläufige Eindeutigkeiten; ${ }^{42}$ ihre Verabsolutierung führt ans Kreuz. Man könnte sagen: In dem Geschehen von Kreuz und Auferstehung werden alle Identifizierungen, Eindeutigkeitsbestimmungen und Verurteilungen von Nichteindeutigkeit ihrer Ambivalenz überführt: Lebensmöglichkeiten sichern zu wollen, jedoch in diesem Bemühen irren zu können. Als nichteindeutig und unverständlich kann danach nicht mehr jemand identifiziert werden. Der Glaube, Eindeutiges und Nichteindeutiges nach einer ewigen Ordnung bestimmen zu können, erweist sich vielmehr als Illusion und Ausdruck von Sünde. Sünde kann in diesem Zusammenhang als die aus der Gottvergessenheit herrührende, verdrehte Selbsteinschätzung bestimmt werden, in der sich der Mensch als Herr über Eindeutigkeit und Ganzheit, als Bezwinger seines Woher ${ }^{43}$ und Wohin, als Sieger über die Sinnlosigkeit und Vieldeutig-

41 Alle Evangelien thematisieren die Überforderung der Jünger mit Jesu erwartetem und faktischem Ende am Kreuz.

42 Die konstitutive Nichteindeutigkeit beschreibt Tillich als Zweideutigkeit der Existenz, der die Möglichkeit der Entfremdung innewohnt. Der Grund für die Zweideutigkeit der menschlichen Existenz und Lebensvollzüge ist nach Tillich eine notwendige Folge des Übergangs von potenziellem (essenziellem) in aktuales Sein (Tillich, 1955).

43 Jüngel: »Indem der Mensch das Nichts als das von ihm selbst bezwungene Woher seiner selbst ausgibt, liefert er sich dem Nichts als dem unbezwingbaren Ziel seiner selbst aus; Gott ist ja aus dem Streit mit dem Nichts in dem 
keit versteht. Sünde ist das »Aus-Sein auf vollständige und dauerhafte Ich-Identität, das die Bedingungen von Fragmentarität nicht zu akzeptieren bereit ist « (Jüngel, 1986) ${ }^{44}$ und damit die oben bestimmte konstitutive Nichteindeutigkeit der eigenen Leiblichkeit ausblendet.

Das vereindeutigende Lesbarmachen der geschaffenen Wirklichkeit fördert immer nur relative Eindeutigkeit und beruht auf der Setzung des Nicht-Eindeutigen - sie ist eine Eindeutigkeit in Grenzen, die sich als lebensdienliche Ordnung bewähren muss. Die allen Ordnungsentwürfen inhärente Setzung von Eindeutigkeit und Nichteindeutigkeit ist als Verwirklichung des Anliegens, Lebensmöglichkeiten zu schaffen, gottgewollt. Die konkrete Setzung von Eindeutigkeit und Nichteindeutigkeit, die Grenzziehung zwischen dem Lesbaren und Anerkannten und dem Nichtlesbaren und Verstoßenen, kann sich nicht auf ein nicht verhandelbares, absolutes Gesetz berufen, sondern entspringt allein menschlichem Ordnungsbemühen.

Kreuz und Auferstehung führen das menschliche Ordnungsbemühen an die Schwelle zwischen Leben und Tod. Sie konfrontieren den Menschen darin mit seiner Abgründigkeit, seinem Scheitern, eine letztgültige Ordnung schaffen zu können: Das Kreuz offenbart (im Licht der Auferstehung) die Wahrheit des menschlichen Strebens nach Eindeutigkeit. Für das Fremde im Anderen, das Nichtverstandene, Nichteindeutige kann nicht irgendjemand, irgendetwas irgendwo zur Rechenschaft gezogen werden. Das Nichteindeutige haftet an meiner geschöpflichen, leibhaften, sozialen Existenz.

Zugleich begründen Kreuz und Auferstehung die Hoffnung auf endzeitliche Vollendung und auf das unmissverständliche Offenbarwerden des Wesens alles Geschaffenen. Sie ermöglichen damit ein

Maße herausgehalten, in dem der Mensch selber aus dem Nichts zu kommen (statt: daraus hervorgerufen zu sein) beansprucht. Dadurch wiederum wird das Nichts mächtig. So wird die Sünde zur creatrix divinitatis, einer Gegen-Gottheit nämlich, deren vernichtende Macht darin besteht, den wahren Gott von sich fernzuhalten« (1986, S. 305f., Fn. 73).

44 »Der Glaubende unterscheidet sich vom Sünder nicht dadurch, daß er der endlich mit sich selbst identisch gewordene Mensch ist. Sondern vom Sünder unterscheidet sich der Glaubende dadurch, daß er nicht mehr mit sich identisch zu werden braucht. Als Glaubender ertrage ich die Unterscheidung des Menschen von sich selbst, indem ich Gott zwischen mir und mir wohnen lasse [...]« (Jüngel, 1996, zit. n. Luther, 1992, S. 172). 
Leben - hier und jetzt - trotz aller Nichteindeutigkeit: Wer der konstitutiven und prinzipiellen Nichteindeutigkeit gewahr wird, muss nicht an den Vieldeutigkeiten des Lebens verzweifeln, sondern kann mit dem gewonnen realistischen Blick auf die begrenzte Leistungsfähigkeit menschlich gewonnener Eindeutigkeiten angstfrei die geschaffene Wirklichkeit gestalten.

Für die Frage nach dem Umgang mit Intersex, d. h. mit geschlechtlicher Nichteindeutigkeit und Vieldeutigkeit, bedeutet das Folgendes: In befriedeten, sozial stabilisierten Gesellschaften wird niemand gekreuzigt und die Sündenbockmechanismen sind nicht leicht zu entlarven. Der Umgang mit Intersex kann als solch ein Ausschluss- oder Sündenbockmechanismus verstanden werden. In den wenigsten Fällen erweisen sich die Eingriffe zur Korrektur des körperlich-geschlechtlich Nichteindeutigen als lebensförderlich. Es handelt sich vielmehr um den Ausschluss, die Verdammung des unverstandenen beängstigenden Anderen. Die hochtechnisierte Medizin schneidet das Vieldeutige aus dem Leib. Der vermeintlichen medizinischen Hilfestellung für IntersexSäuglinge geht die Sanktionierung des Schwer-Lesbaren, des Nichteindeutigen, Anders-Gestalteten voraus, das zum Schutz der erhaltenden Ordnung vernichtet wird. Die medizinisch-technische »Sorge « um Menschen nicht typischer Geschlechtlichkeit verdrängt das nicht auszulöschende Unverstandene menschlicher Existenz. Das Bedürfnis, eine - theologisch betrachtet kontingente und deshalb grundsätzlich verhandelbare - menschliche Ordnung zu sichern, gipfelt in einem totalitären medizinischen Imperativ, in dessen Namen Gewalt gerechtfertigt wird. ${ }^{45}$ 


\section{Intersexualität als theologische Herausforderung}

Die biologisch-medizinische Perspektive auf Geschlechtlichkeit verweist darauf, dass sich Geschlecht als Kontinuum mit graduellen Unterschieden darstellt statt als dichotom-binär mit möglichen Zwischentönen. Der gewöhnliche kategorial-begriffliche Rahmen zur Beurteilung von geschlechtlicher Eindeutigkeit und Nichteindeutigkeit versagt, zeigt sich Geschlecht doch als mehrdeutig, und zwar nicht nur im Sinne sexueller Orientierung oder geschlechtlich interpretierter sozialer Rolle, sondern schon als biologisches Geschlecht. Wenn wir diesen Umstand ernst nehmen, benötigen wir »ein Verständnis dafür, dass Säuglinge mit Intersex-Voraussetzungen Teil des Kontinuums menschlicher Morphologie sind und in der Annahme behandelt werden sollten, dass ihr Leben nicht nur lebenswert ist und sein wird, sondern auch eine Chance des Gedeihens ist « (Butler, 2009, S. 14).

Eine Beschäftigung mit der Theoriegeschichte offenbart, dass sich das gegenwärtige Geschlechterverständnis nicht auf eine übergeschichtliche Selbstverständlichkeit berufen kann. Die mit den Geschlechterkategorien verbundenen normativen Ansprüche sowie ihre empirische Füllung waren schon immer umstritten. Allein aus diesen Gründen liegt ein flexiblerer Umgang mit ihnen nahe.

Konstruktivistische Ansätze unterstreichen, dass es sich bei der Diskrepanz zwischen vulgärem Geschlechterverständnis und dessen Dekonstruktion (z.B. aus medizinisch-biologischer Perspektive) nicht nur um eine Spannung zwischen Naturordnung und Kulturordnung handelt, sondern dass beide Ordnungen aufs Engste miteinander ver- 
woben sind und die vermeintlich natürliche »Wirklichkeit an sich « allenfalls in ihrer Widerständigkeit erfahren wird. Die Wirklichkeit, die allen begrifflichen Feststellungsversuchen widerstrebt, drückt sich nicht nur in der von kontingenten Referenzpunkten abhängigen geschlechtlichen Vieldeutigkeit aus, sondern auch in der reflexiven NichtEinholbarkeit der leiblichen Selbsterfahrung eines jeden Menschen. Sie verweist dabei als ontologische und epistemologische Einsicht auf eine prinzipiell vorbehaltliche Gültigkeit menschlicher Versuche, die Wirklichkeit zu ordnen, zu kategorisieren und zu gestalten.

Theologisch wurden Geschlecht und die faktische geschlechtliche Nichteindeutigkeit mithilfe des Leibbegriffs umrissen: Die geschlechtliche Vieldeutigkeit und Nichteindeutigkeit muss theologisch genauer bestimmt werden als Aspekt des Leibes, der als Ganzer letztlich unerschlossen, unverständlich und unverfügbar bleibt. Geschlecht als soziale Kategorie wurde unter Zuhilfenahme des Lehrstücks von der Schöpfungsordnung thematisiert: In dieser Perspektive erscheint Geschlecht nicht nur als präskriptiver Begriff (im Sinne einer Kongruenzforderung von Geschlechtsrolle, Sexualität und biologischem Geschlecht) unhaltbar; schon als deskriptiver Begriff ist Geschlecht theologisch nur schwer plausibel zu machen. Gott schuf den Menschen nicht nur als Mann und Frau. Und seine Erschaffung gipfelt nicht in seiner Geschlechtlichkeit. Gott schuf die Menschen für sich und füreinander das ist die die eigentliche Pointe der Schöpfungsberichte und die zentrale christliche Aussage über den Menschen als relationales Wesen. Die Engführung von personaler Identität auf reproduktive Fähigkeiten und ein damit gefordertes Festhalten an Geschlechterkategorien als theologischen Fixpunkten, kann biblisch und systematisch-theologisch nicht begründet werden. Wenn sich der Mensch coram deo nicht durch seine Geschlechtlichkeit auszeichnet, was bedeutet das für den Menschen coram mundo?

»Was könnte es bedeuten, mit der Beunruhigung durch diese Herausforderung leben zu lernen - zu spüren, wie sich die Sicherheit der eigenen epistemologischen und ontologischen Verankerung verflüchtigt, und gleichwohl im Namen des Menschlichen den Willen aufzubringen, dem Menschlichen zuzubilligen, etwas anderes zu werden als das, für das man es traditionellerweise hält? « (Butler, 2009, S. 63). 
Die Relativierung des Selbstverständlichen würdigt die christliche Tradition mit Kreuz und Auferstehung in zwei sehr starken Symbolen. Das in menschlicher Perspektive Unverstandene, Vieldeutige wird darin nicht als das aus der göttlichen Ordnung Ausgestoßene bestätigt, sondern im Gegenteil: Das Nichteindeutige erweist sich gerade als das Angenommene. Die Ordnungen und die sich aus der Ordnungsgestalt ergebende Bestimmung des (Nicht-)Eindeutigen, das aus der Ordnung fällt, werden als Menschenwerk entlarvt und damit grundsätzlich infrage gestellt. Der Erweis des Nichteindeutigen als Folge der menschlichen Setzung von Nicht-/Eindeutigkeit fordert dazu auf, menschliche Ordnungen der Sinngebung und Wirklichkeitsgestaltung auf ihre Lebensdienlichkeit hin zu befragen und zu korrigieren. Die Geschlechterordnung, die nicht nur auf identitären Feststellungen des Männlichen und Weiblichen beruht, sondern auch einen Bereich des Ausgegrenzten, Nichtintelligiblen schafft, ist nicht um ihrer selbst willen als quasi göttliche geheiligt. Allein der sie hervorbringende Versuch, die geschaffene Welt verstehbar und gestaltbar zu machen, ist göttlich legitimiert - und damit zugleich verschiedene mögliche Ordnungsgestalten. 


\section{Ausblick}

Die theologische Antwort auf die faktisch plurale Geschlechtermorphologie kommt an der selbstkritischen Überprüfung, welchen Stellenwert geschlechtsbasierte und heteronormative Denkfiguren in theologischen Systemen einnehmen, nicht vorbei. Die Frage nach der Lebensdienlichkeit geschlechtsfixierter sozialer Ordnungen und der Orientierung an Geschlecht als Ordnungskategorie überhaupt, muss vor allem im Rahmen ethischer Aushandlungs- und Abwägungsarbeit bedacht werden. In der Stellungnahme des Deutschen Ethikrats (2012) wird nicht erwähnt, dass auch sechs Theolog_innen dem Rat angehören. Von der gesellschaftlichen Verantwortung der Kirchen, sich dieses Themas anzunehmen und für eine gleichberechtigte Teilhabe von Intersexen an unserer Gesellschaft einzutreten, ist noch nichts zu spüren.

Wenn die faktische geschlechtliche Pluralität doch eine sehr grundsätzliche Anfrage darstellt und ein langfristiges Umdenken unumgänglich scheint, müssen die akuten kirchlichen Hilfestellungen auch auf die aus der Überforderung einer faktisch heteronormativ denkenden Gesellschaft erwachsenden Herausforderungen reagieren: Eltern von Intersex-Kindern werden zwischen dem gesellschaftlichen Druck zur Vereindeutlichung und der unmittelbaren Sorge um das physische Wohl ihres Kindes aufgerieben und benötigen auch seelsorgerische Begleitung.

Aus konstruktivistischer Sicht stellt sich nicht nur die Frage nach den Geschlechterkonfigurationen, die theologisch durch Zitation von bestimmten geschlechtlichen Denkräumen perpetuiert werden (Gen- 
dering bzw. Doing gender). Es geht nicht nur um die Substitution zu eng gefasster Geschlechterkonfigurationen, sondern darum, die Sexuierung/Vergeschlechtlichung von Lebensbereichen grundsätzlich infrage zu stellen. Auch wenn die aus der Beschäftigung mit Intersex erwachsende Kritik mit der Forderung einer dritten Geschlechterkategorie nicht ihr Ende findet, sondern Geschlechterkategorie überhaupt infrage stellt (Janssen, 2009, S. 178), besteht mittelfristig ein politisch und auch kirchlich-theologisch unterstützenswerter Schritt gegen Diskriminierung von Intersexen in der Einführung weiterer Geschlechterkategorien.

Die Wahrnehmung des Menschen als die eines geschlechtlich vieldeutigen Wesens erschöpft sich nicht in der theoretischen Dekonstruktion von Geschlecht und Geschlechterkonfigurationen. So fragt Janssen: »Wo in den Texten bleiben die Individuen, die durch die Durchsetzung der Norm Zweigeschlechtlichkeit häufig für ein Leben lang verletzt werden? « (2009, S. 165). Es braucht Intersex-Narrative, um die aus der theoretischen Einsicht erwachsende Kritik um die vielgestaltigen Perspektiven geschlechtlichen Selbsterlebens zu ergänzen.

»Das Übergehen eines praktischen Anspruchs der eigenen Theorieproduktion schafft Nicht-Positionierungen, die Intersexualität diskursiv ausbeuten. Die zum Zweck der Bearbeitbarkeit erforderliche Verobjektivierung intersexueller Menschen verhindert deren Positionierung als Akteur_innen im Feld >Intersexualität< und erschwert immens die Bildung eines herrschaftssensiblen und parteiischen Wissens « (ebd., S. 181).

Darüber hinaus wird nur in der Zusammenfassung unterschiedlicher Intersex-Narrative deutlich, dass Intersex $\gg$ von Aktivist_innen weder einheitlich als verbindendes Wesensmerkmal noch als strategische Bündnisidentität verstanden « (ebd., S. 169) wird. Die Intersex-Bewegung ist eine heterogene Bewegung, auch in ihrer Beurteilung von Geschlecht und Geschlechterkategorien, die in der Konstituierung einer vermeintlich einheitlichen, geschlechtlich nichteindeutigen Gruppe unsichtbar werden (ebd., S. 178).

Die Stärkung und das Einbringen der Intersex-Perspektive darf nicht als Scheinauseinandersetzung auf die Bereiche Kunst, Mythologie und 
Geschichte beschränkt bleiben. Es muss deutlich werden, dass es nicht um das entrückte Unverstandene und Rätselhafte geht, sondern um Menschen aus unserer Gesellschaft. Eine bloße Auseinandersetzung mit vergangenen Darstellungen und dem einstigen Umgang mit Intersex läuft Gefahr, dessen Exotisierung und Anomalisierung fortzuschreiben (ebd., S. 173).

Das Selbsterleben von Intersexen ernst zu nehmen bestärkt die z. B. von schwul-lesbischer Seite immer wieder vorgetragene Kritik an der kirchlich-rituellen Privilegierung bestimmter Beziehungs- und Lebensformen. Die Kopplung des ehelichen Segens an eine bestimmte Geschlechterkonfiguration arbeitet unter einer normativen Voraussetzung, die in der christlichen Botschaft gerade nicht gegeben ist und die ihr Ziel, Menschen für ihre verantwortliche Lebensgestaltung den Segen Gottes zuzusprechen, verfehlt. Diesem Einwand kann mit dem Rekurs auf die besondere reproduktive Verantwortung der Mann-FrauBeziehung nur schwer begegnet werden. So ist die heterosexuelle Ehe längst nicht mehr die einzige Sozialform, um Kinder großzuziehen. Adoptiv-, Stief- und Leihelternschaft sind keine gesellschaftlichen Ausnahmephänomene mehr. Auch der enorme Fortschritt der Reproduktionsmedizin, die Technologisierung von Geburt und nicht zuletzt die damit einhergehenden gesellschaftlichen und wirtschaftlichen Zwänge werden von Menschen sehr unterschiedlich erlebt (Scheuter \& Oldenhage, 2008, S. 45) und sie tun das Ihre, um »romantisierende Vorstellungen von > natürlicher $<$ Schwangerschaft und Geburt « (ebd., S. 46) zu destruieren.

Eine kritische Sichtung der theologischen Traditionsbestände darf bei allen praktischen Handlungsimpulsen nicht ausbleiben. ${ }^{46}$ Sie könnte einen Paradigmenwechsel für den kirchlichen Umgang mit geschlechtlicher Nichteindeutigkeit sogar fördern, indem sie Denkräume sowohl für Geschlecht als auch jenseits davon erschließt, die in der alltäglichen

46 Karle (2006) hinterfragt die neuere evangelische Sozialethik auf ihren Umgang mit zweigeschlechtlichen Denkfiguren, namentlich Wolf (1988), Rendtorff (1991), Honecker (1995), Körtner (1999) und Korsch (2000). Auch wenn sich die untersuchten Aufrisse hinsichtlich ihres Umgangs mit gendertheoretischen Konzepten sehr unterscheiden, gehen sie doch alle »selbstverständlich von der Natürlichkeit und Nichtkontingenz der Zweigeschlechtlichkeit aus« (Karle, 2006, S. 200). 
Enthistorisierung von Geschlecht nicht in Betracht kommen. ${ }^{47}$ Dass nicht nur das Verhältnis der beiden vermeintlichen Idealgeschlechter immer wieder auch theologischer Diskussionsgegenstand war, sondern ebenso die Frage, was genau unter dem »natürlichen Substrat « von Geschlecht zu verstehen ist, zeigt ein Blick in erste einschlägige Quellensammlungen zu diesem Thema (z. B. Gössmann, 1998). So war z. B. bis zur Reformationszeit die Nonne das Ideal einer Frau, bis »Martin Luther die weltliche Ehefrau und Mutter, die die christliche Moral in der Familie hütet, zum neuen weiblichen Ideal « (Scheuter \& Oldenhage, 2008, S. 41) erklärte.

Ein besonderer Wert gebührt der kirchen-, dogmen- und theologiegeschichtlichen Arbeit für die Aufgabe, zu klären, inwieweit Theologie mit der geschlechtlichen Fixierung mit dem Beginn der Moderne nur auf einen allgemeinen Trend zu Naturalisierung, Biologisierung und damit Transzendentalisierung der Geschlechtlichkeit reagiert oder ob sie diese durch das aus einer engen Genesis-Hermeneutik erwachsene heterosexuelle Missverständnis aktiv gefördert hat. ${ }^{48}$

Schließlich müssen die Verschleierungsmechanismen bearbeitet werden, die eine grundsätzliche Auseinandersetzung mit geschlechtlicher Pluralität verhindern. Das ist der Fall, wenn die Herausforderung durch Intersexe - an der Pathologisierung festhaltend - ${ }^{49}$ auf die diakonische Arbeit beschränkt wird. Auch der Rekurs auf die ökumenische Rücksichtnabme, um an Pathologisierung und Vergeschlechtlichung festzuhalten,

47 Dass z. B. die Vorstellung einer goldenen Geschlechter-Vorzeit auf einer retrospektiven Projektion beruht und dass die frühchristlichen Männlichkeitsideale in höchstem Maße irritierend für heutige sogenannte konservative Vorstellungen insbesondere der männlichen Geschlechterrolle sind, zeigt Krondorfer (2008, S. $57 f f$.$) .$

48 Das geschlechtlich »Abnorme« gerät in einer zunehmend vergeschlechtlichten Gesellschaft in den Fokus. Als entscheidend beteiligt an der Eintragung von Geschlecht in unterschiedliche Lebenszusammenhänge und an der Moralisierung des Sexuellen betrachtet Michel Foucault (1983) insbesondere die kirchliche Beicht- und Bußpraxis. Durch die heilsrelevante Aufladung wird Geschlecht zu einem entscheidenden Kriterium für die Zubilligung von Rechten und Pflichten innerhalb der Sozialgestalten christlichen Lebens in Ehe, Priesterstand usw. Abweichung und sexuelle Nonkonformität werden in dieser Logik mit dem Tod bestraft.

49 Diese Haltung zum Phänomen bezeichnet (Wiesemann, 2010; zit. n. Deutscher Ethikrat, 2012, S. 103) zu Recht als benevolenten Paternalismus. 
kann zur Verschleierung dienen. Er blendet die Heterogenität der Christentümer aus und verkennt die Historizität der eigenen Geschlechterund Menschenbilder. 


\section{Literatur}

AG Queer Studies (Hrsg.). (2009). Verqueerte Verhältnisse. Intersektionale, ökonomiekritische und strategische Interventionen. Hamburg: Männerschwarm Verlag.

Alloa, E. \& Depraz, N. (2012). Edmund Husserl - „Ein merkwürdig unvollkommen konstituiertes Ding «. In E. Alloa, T. Bedorf, C. Grüny \& T. N. Klass (Hrsg.), Leiblichkeit (S. 7-22). Tübingen: Mohr-Siebeck.

Alloa, E., Bedorf, T., Grüny, C. \& Klass, T. N. (Hrsg.). (2012). Leiblichkeit. Tübingen: MohrSiebeck.

Angerer, M. L. (2012). Gender und Performance - Ist leibliche Identität ein Konstrukt? In E. Alloa, T. Bedorf, C. Grüny \& T. N. Klass (Hrsg.), Leiblichkeit (S. 334-350). Tübingen: Mohr-Siebeck.

Barad, K. (2012). Agentieller Realismus. Über die Bedeutung materiell-diskursiver Praktiken. Berlin: edition unseld. (Engl. Orig. [2003]. Agential Realism. How materialdiscursive practices matter.)

Bedorf, T. (2012). Emmanuel Levinas - Der Leib des Anderen. In E. Alloa, T. Bedorf, C. Grüny \& T. N. Klass (Hrsg.), Leiblichkeit (S. 68-80). Tübingen: Mohr-Siebeck.

Bolken, E. \& Thies, C. (Hrsg.). (2009). Handbuch Anthropologie. Der Mensch zwischen Natur, Kultur und Technik. Stuttgart und Berlin: Metzler'sche Verlagsbuchhandlung.

Bourdieu, P. (2005). Die männliche Herrschaft. Frankfurt a. M.: Suhrkamp. (Frz. Orig. [1998]. La domination masculine.)

Braun, C. von \& Stephan, I. (Hrsg.). (2005). Gender@Wissen. Ein Handbuch der GenderTheorien. Köln: Böhlau Verlag.

Brüske, A., Miko Iso, I., Wespe, A., Zehnder, K. \& Zimmermann, A. (Hrsg.). (2011). Szenen von Widerspenstigkeit. Geschlecht zwischen Affirmation, Subversion und Verweigerung. Frankfurt a. M. und New York: Campus Verlag.

Butler, J. (1991). Das Unbehagen der Geschlechter (15. Aufl.). Frankfurt a. M.: Suhrkamp. (Engl. Orig. [1990]. Gender trouble.)

Butler, J. (1995). Körper von Gewicht. Frankfurt a. M.: Suhrkamp. (Engl. Orig. [1993]. Bodies that matter.)

Butler, J. (2009). Die Macht der Geschlechternormen und die Grenzen des Menschlichen. Frankfurt a. M.: Suhrkamp. (Engl. Orig. [2004]. Undoing gender.) 
Butler, J. (2013). Das Gespräch: Interview mit Judith Butler. Philosophie Magazin, (1), 64-69.

Deutscher Ethikrat (Hrsg.). (2012). Intersexualität. Stellungnahme. Berlin.

Dierken, J. (2005). Selbstbewusstsein individueller Freiheit. Religionstheoretische Erkundungen in protestantischer Perspektive. Tübingen: Mohr-Siebeck.

EKD - Evangelische Kirche in Deutschland (1981a). Ehe, Familie, Frauen und Männer. Hannover.

EKD - Evangelische Kirche in Deutschland (1981b). Zu Fragen der Sexualethik. Hannover.

EKD - Evangelische Kirche in Deutschland (1996). Mit Spannung leben. Hannover.

EKD - Evangelische Kirche in Deutschland (2004). Verlässlichkeit und Verantwortung stärken. Eine Stellungnahme des Kirchenamtes der EKD zur Verbesserung des Rechtsschutzes für gleichgeschlechtliche Lebenspartnerschaften und zur besonderen Bedeutung der Stellung der Ehe. Hannover.

EKD - Evangelische Kirche in Deutschland (2013). Zwischen Autonomie und Angewiesenheit. Familie als verlässliche Gemeinschaft stärken. Hannover.

Ellison, M. M. (2004). Sexualität. VII. Biologisch und medizinisch. In H. D. Betz, D. S. Browning, B. Janowski \& E. Jüngel (Hrsg.), Religion in Geschichte und Gegenwart (4. Aufl.; Bd. 7; S. 1258-1260). Tübingen: Mohr Siebeck.

Evers, D. (2000). Gesetz/Naturgesetz. In H. D. Betz, D. S. Browning, B. Janowski \& E. Jüngel (Hrsg.), Religion in Geschichte und Gegenwart (4. Aufl.; Bd. 3; S. 855-858). Tübingen: Mohr Siebeck.

Evers, D. (2010). Zwei Perspektiven und die eine Wirklichkeit. Anregungen zum Diskurs zwischen Glauben und Wissenschaft. Herrenalber Forum, Bd. 62. Hrsg. von der Evangelischen Akademie Baden und dem Freundeskreis der Evangelischen Akademie Baden e. V., Karlsruhe.

Evers, D., Fuller, M., Jackelén, A. \& Smedes, T. A. (Hrsg.). (2012). Is Religion Natural? London und New York: T\&T Clark International.

Evers, D. (2014). Wirklichkeit - »Was der Fall ist« oder »Wie es Euch gefällt«? In B. A. Weinhardt \& J. Weinhardt (Hrsg.), Naturwissenschaften und Theologie II. Wirklichkeit: Phänomene, Konstruktionen, Transzendenzen (S.91-107). Stuttgart: Kohlhammer.

Fausto-Sterling, A. (2000). Sexing the body. Gender Politics and the Construction of Sexuality. New York: Basic Books.

Ferrari-Schiefer, V. (1998a). La Belle Question. Die Frage nach der Gleichheit der Geschlechter bei Francois Poullain de la Barre (1647-1723) vor dem Hintergrund der (früh-)neuzeitlichen Querelle des Femmes (Theologie in Geschichte und Gesellschaft 8). Luzern: Edition Exodus.

Ferrari-Schiefer, V. (1998b). Gleichheit, Differenz und Gleichwertigkeit der Geschlechter - Ein philosophie- und theologiegeschichtlicher Beitrag zu einer nach wie vor kontroversen Diskussion. Schweizerische Kirchenzeitung, (14). http://www. kath.ch/skz-1998/theologie/th14.htm (24.01.2013).

Ferruta, P. (2010). Naturwissenschaftliche Auffassung des Menschen, symbolische Gesellschaftsordnung und geschlechtlich codierte Moralphysiologie in der saint-simonistischen Bewegung um 1830. Geschlecht - Wissen - Geschichte. Österreichische Zeitschrift für Geschichtswissenschaften, 21(1), 37-64.

Foucault, M. (1983). Der Wille zum Wissen. Sexualität und Wahrheit I. Frankfurt a. M.: Suhrkamp (Frz. Orig. [1976] La volonté de savoir.) 
Foucault, M. (2012). Über Hermaphroditismus. Der Fall Barbin (4. Aufl.). Hrsg. von W. Schäffner \& J. Vogl. Frankfurt a. M.: Suhrkamp. (Frz. Orig. [1978]. Herculine barbin dite Alexine $B$.)

Gallie, W. B. (1956). Essentially Contested Concepts. Proceedings of the Aristotelian Society, 56(1), 167-198.

Girard, R. (2008). Ich sah den Satan vom Himmel fallen wie einen Blitz. Eine kritische Apologie des Christentums. Frankfurt a. M.: Verlag der Weltreligionen. (Fz. Orig. [1999]. Je vois Satan tomber comme l'éclaire.)

Goffman, E. (1994). Das Arrangement der Geschlechter. In E. Goffman \& H. A. Knoblauch (Hrsg.), Interaktion und Geschlecht. Frankfurt a. M. und New York: Campus Verlag.

Goldschmidt, R. (1915). Vorläufige Mitteilung über weitere Versuche zur Vererbung und Bestimmung des Geschlechts. Biologisches Centralblatt, 35(12), 565-570.

Gössmann, E. (1998). Archiv für philosophie- und theologiegeschichtliche Frauenforschung (2. Aufl.; 8 Bde.). München: ludicum Verlag.

Gross, S. (1999). Intersexuality and Scripture. Theology and Sexuality, 11(6), 65-74.

Grosz, E. A. (1996). Intolerable Ambiguity. Freaks as/at the Limit. In R. Garland Thomson (Hrsg.), Freakery. Cultural Spectacles of the Extraordinary Body (S. 55-66). New York: NYU Press.

Grosz, E. A. (2005). Time travels: feminism, nature, power. Crows Nest/Australia: Allen \& Unwin.

Härle, W. (2002). Mensch. VII. Dogmatisch und Ethisch. In H. D. Betz, D. S. Browning, B. Janowski \& E. Jüngel (Hrsg.), Religion in Geschichte und Gegenwart (4. Aufl.; Bd. 5; S. 1066-1072). Tübingen: Mohr Siebeck.

Härle, W. (2007). Dogmatik (3., überarb. Aufl.). Berlin: Walter de Gruyter.

Henry, M. (1965). Philosophie et phénoménologie du corps. Essai sur l'ontologie biranienne. Paris: PUF.

Henry, M. (2002). Inkarnation. Eine Philosophie des Fleisches. Freiburg und München: Alber. (Frz. Orig. [2000]. Incarnation. Une philosophie de la chair.)

Herms, E. (1991). Gesellschaft gestalten. Beiträge zur evangelischen Sozialethik. Tübingen: Mohr Siebeck.

Herms, E. (1992). Offenbarung und Glaube. Zur Bildung des christlichen Lebens. Tübingen: Mohr Siebeck.

Herms, E. (2004). Schöpfungsordnung. In H.D. Betz, D. S. Browning, B. Janowski \& E. Jüngel (Hrsg.), Religion in Geschichte und Gegenwart (4. Aufl.; Bd. 7; S. 990-992). Tübingen: Mohr Siebeck.

Herms, E. (2005). Vernunft. II. Religionsphilosophisch. III. Fundamentaltheologisch. IV. Dogmatisch. V. Ethisch. In H. D. Betz, D. S. Browning, B. Janowski \& E. Jüngel (Hrsg.), Religion in Geschichte und Gegenwart (4. Aufl.; Bd. 8; S. 1039-1045). Tübingen: Mohr Siebeck.

Herms, E. (2007). Zusammenleben im Widerstreit der Weltanschauungen. Beiträge zur Sozialethik. Tübingen: Mohr Siebeck.

Heß, R. (2005). »Es ist noch nicht erschienen, was wir sein werden.« Biblisch-(de)konstruktivistische Anstöße zu einer entdualisierten Eschatologie der Geschlechterdifferenz. In R. Heß \& M. Leiner (Hrsg.), Alles in allem. Eschatologische Anstöße (FS für Christine Janowski) (S. 291-324). Neukirchen-Vluyn: Neukirchener Verlag.

Heß, R. \& Leiner, M. (Hrsg.). (2005). Alles in allem. Eschatologische Anstöße (FS für Christine Janowski). Neukirchen-Vluyn: Neukirchener Verlag. 
Heß, R. (2011). Ursprungsnarrationen zwischen Affirmation und Subversion: Judith Butler und Joseph Ratzinger. In A. Brüske, I. Miko Iso, A. Wespe, K. Zehnder \& A. Zimmermann (Hrsg.), Szenen von Widerspenstigkeit. Geschlecht zwischen Affirmation, Subversion und Verweigerung (S. 119-140). Frankfurt a. M. und New York: Campus Verlag.

Honecker, M. (1995). Grundriß der Sozialethik. Berlin und New York: De Gruyter.

Honegger, C. (1991). Die Ordnung der Geschlechter. Die Wissenschaften vom Menschen und das Weib 1750-1850. Frankfurt a. M. \& New York: Campus Verlag.

Höpflinger, A.-K., Jeffers, A. \& Pezzoli-Oligati, D. (Hrsg.). (2008). Handbuch Gender und Religion. Göttingen: Vandenhoeck \& Ruprecht.

Hull, C. (2006). The Ontology of Sex: A Critical Inquiry into Deconstruction and Reconstruction of Categories. London und New York: Routledge.

Husserl, E. (2008). Husserliana XXXIX: Die Lebenswelt. Auslegungen der vorgegebenen Welt und ihrer Konstitution. Texte aus dem Nachlass (1893-1912). Hrsg. von R. Sowa. Dordrecht, NL: Springer.

Huxel, K. (2002). Leib/Leiblichkeit. III. Ethisch. In H. D. Betz, D. S. Browning, B. Janowski \& E. Jüngel (Hrsg.), Religion in Geschichte und Gegenwart (4. Aufl.; Bd. 5; S. 220-221). Tübingen: Mohr Siebeck.

Intersexuelle Menschen e.V. (Hrsg.). (2008). Schattenbericht zum 6. Staatenbericht der Bundesrepublik Deutschland zum Übereinkommen der Vereinten Nationen zur Beseitigung jeder Form der Diskriminierung der Frau (CEDAW). Hamburg.

Intersexuelle Menschen e.V. (Hrsg.). (2011). Parallelbericht zum 5. Staatenbericht der Bundesrepublik Deutschland zum Internationalen Pakt der Vereinten Nationen über wirtschaftliche, soziale und kulturelle Rechte (CESCR). Hamburg.

Irigaray, L. (1991). Ethik der sexuellen Differenz. Frankfurt a. M.: Suhrkamp. (Frz. Orig. [1984]. Éthique de la différance sexuelle.)

Janssen, C. (2001). Nicht mehr männlich? Gal 3,28 und das Streitfeld Maskulinität. In C. Janssen, L. Schottroff \& B. Wehn (Hrsg.), Paulus. Umstrittene Traditionen - lebendige Theologie: Eine feministische Lektüre. Gütersloh: Gütersloher Verlagshaus.

Janssen, C. (2005). Anders ist die Schönheit der Körper. Paulus und die Auferstehung in 1Kor 15. Gütersloh: Gütersloher Verlagshaus.

Janssen, J. (2009). Theoretisch intersexuell. Wie intersexuelle Menschen zwischen den Zeilen bleiben. In AG Queer Studies (Hrsg.), Verqueerte Verhältnisse. Intersektionale, ökonomiekritische und strategische Interventionen (S. 165-184). Hamburg: Männerschwarm Verlag.

Jüngel, E. (1986). Gott als Geheimnis der Welt. Zur Begründung der Theologie des Gekreuzigten im Streit zwischen Theismus und Atheismus (5., durchges. Aufl.). Tübingen: Mohr Siebeck.

Karle, I. (2006). »Da ist nicht mehr Mann noch Frau ... «: Theologiejenseits der Geschlechterdifferenz. Gütersloh: Gütersloher Verlagshaus.

Kirby, V. (1997). Telling flesh. The Substance of the Corporeal. New York und London: Routledge.

Koch, T. (1978). Der Leib und die Natur. Zum christlichen Naturverständnis. Neue Zeitschrift für systematische Theologie und Religionsphilosophie, 20(3), 295-316.

Koch, T. (1992). Mensch: VIII. 19. und 20. Jahrhundert. IX. Systematisch-theologisch. In G. Müller (Hrsg.), Theologische Realenzyklopädie (22 Bde.; S. 530-567). Berlin: De Gruyter. 
Korsch, D. (2000). Dogmatik im Grundriss. Eine Einführung in die christliche Deutung menschlichen Lebens mit Gott. Tübingen: Mohr Siebeck.

Körtner, U. H. J. (1999). Evangelische Sozialethik. Grundlagen und Themenfelder. Göttingen: Vandenhoeck \& Ruprecht.

Körtner, U.H.J. (2004). Sexualität. I. Religionswissenschaftlich. II. Theologisch und anthropologisch. IV. Ethisch. In H. D. Betz, D. S. Browning, B. Janowski \& E. Jüngel (Hrsg.), Religion in Geschichte und Gegenwart (4. Aufl.; Bd. 7; S. 1246-1247, 1247-1248, 1250-1253). Tübingen: Mohr Siebeck.

Kristensen, S. (2012). Maurice Merleau-Ponty I - Körperschema und leibliche Subjektivität. In E. Alloa, T. Bedorf, C. Grüny \& T. N. Klass (Hrsg.), Leiblichkeit (S. 23-36). Tübingen: Mohr-Siebeck.

Krondorfer, B. (2008). Eunuchen oder Viagra? In H. Walz \& D. Plüss (Hrsg.), Theologie und Geschlecht. Dialoge querbeet (S. 71-74). Wien: Lit-Verlag.

Küpper, B. \& Zick, A. (2010). Das Projekt »Gruppenbezogene Menschenfeindlichkeit in Deutschland«. Eine 10-jährige Langzeituntersuchung mit einer jährlichen Bevölkerungsumfrage zur Abwertung und Ausgrenzung von schwachen Gruppen. Hrsg. vom Institut für interdisziplinäre Konflikt- und Gewaltforschung der Universität Bielefeld.

Küpper, B., Zick, A. \& Hövermann, A. (2011). Die Abwertung der Anderen. Eine europäische Zustandsbeschreibung zu Intoleranz, Vorurteilen und Diskriminierung. Hrsg. von der Friedrich-Ebert-Stiftung. Berlin.

Küpper, B. \& Zick, A. (2012). Homophobie in Nordrhein-Westfalen. Sonderauswertung der Studie »Gruppenbezogene Menschenfeindlichkeit». Studie im Auftrag des Ministeriums für Gesundheit, Emanzipation, Pflege und Alter des Landes Nordrhein-Westfalen.

Lange, E. (2002). Ethik in evangelischer Perspektive. Grundfragen christlicher Lebenspraxis (2. Aufl.). Göttingen: Vandenhoek \& Ruprecht.

Laqueur, T.W. (1992). Auf den Leib geschrieben. Die Inszenierung der Geschlechter von der Antike bis Freud. Frankfurt a. M. und New York: Campus Verlag. (Engl. Orig. [1990]. Making Sex. Body and Gender from the Greeks to Freud.)

Levinas, E. (1986). Über die Intersubjektivität. Anmerkungen zu Merlau-Ponty. In A. Métreaux \& B. Waldenfels (Hrsg.), Leibhaftige Vernunft. Spuren von MerleauPontys Denken (S. 48-55). München: Fink.

Levinas, E. (2008). Ethik und Unendliches (4. Aufl.). Wien: Passagen-Verlag. (Frz. Orig. [1982]. Éthique et Infini.)

Link, C. (2003). Wahrnehmung der Natur als Schöpfung. Viktor von Weizsäckers Modell eines Dialogs zwischen Naturwissenschaft und Theologie. In J. Track \& C. Link (Hrsg.), Verstehen - Bewahren - Gestalten. Christliche Orientierung in der Krise der Neuzeit (S. 91-110). Neukirchen-Vluyn: Neukirchener Verlag.

Lorber, J. (1999). Gender-Paradoxien. Opladen: Leske \& Budrich. (Engl. Orig. [1995]. Paradoxes of gender.)

Luther, H. (1992). Religion und Alltag. Bausteine zu einer Praktischen Theologie des Subjekts. Stuttgart: Radius-Verlag.

Merleau-Ponty, M. (1966). Phänomenologie der Wahrnehmung (6. Aufl.). Berlin: Walter de Gruyter. (Frz. Orig. [1945]. Phénoménologie de le perception.)

Métreaux, A. \& Waldenfels, B. (Hrsg.). (1986). Leibhaftige Vernunft. Spuren von MerleauPontys Denken. München: Fink. 
Mühling-Schlapkohl, M. (2004). Relationalität. In H. D. Betz, D. S. Browning, B. Janowski \& E. Jüngel (Hrsg.), Religion in Geschichte und Gegenwart (4. Aufl.; Bd. 7; S. 258-261). Tübingen: Mohr Siebeck.

Nassehi, A. (2003). Geschlecht im System: Die Ontologisierung des Körpers und die Asymmetrie der Geschlechter. In U. Pasero \& C. Weinbach (Hrsg.), Frauen, Männer, Gender Trouble. Systemtheoretische Essays (S. 80-104). Frankfurt a. M.: Suhrkamp.

Neuer Berliner Kunstverein (Hrsg.). (1986). Androgyn. Sehnsucht nach Vollkommenheit (Katalog zur gleichnamigen Ausstellung unter Ursula Prinz). Berlin: Dietrich Reimer Verlag.

Otto, E. (1996). Die Paradieserzählung Gen 2-3. Eine nachpriesterliche Lehrerzählung in ihrem religionshistorischen Kontext. In A. A. Diesel, R. G. Lehmann, E. Otto \& A. Wagner (Hrsg.), »Jedes Ding hat seine Zeit ... «. Studien zur israelitischen und altorientalischen Weisheit (FS für Diethelm Michel) (S. 167-192). Berlin und New York: De Gruyter.

Pannenberg, W. (1991). Systematische Theologie (Bd. 2). Göttingen: Vandenhoeck \& Ruprecht.

Pasero, U. \& Weinbach, C. (Hrsg.). (2003). Frauen, Männer, Gender Trouble. Systemtheoretische Essays. Frankfurt a. M.: Suhrkamp.

Päpstlicher Rat für die Familie (2000). Erklärung des Päpstlichen Rates für die Familie bezüglich der Resolution des Europäischen Parlaments am 16. März 2000, welche alle Arten von Lebenspartnerschaften, einschließlich homosexueller, der Familie gleichstellt.

Plessner, H. (1975 [1928]). Die Stufen des Organischen und der Mensch. Einleitung in die philosophische Anthropologie (3. Aufl.). Berlin und New York: De Gruyter.

Rattner, J. \& Danzer, G. (2009). Medizinische Anthropologie. In E. Bolken \& C. Thies (Hrsg.), Handbuch Anthropologie. Der Mensch zwischen Natur, Kultur und Technik (S. 183-190). Stuttgart und Berlin: Metzler'sche Verlagsbuchhandlung.

Rendtorff, T. (1991). Ethik. Grundelemente, Methodologie und Konkretion einer ethischen Theologie II (2., erw. Aufl.; Bd. 2). Stuttgart und Berlin: Kohlhammer.

Ringleben, J. (2002). Leib/Leiblichkeit. II. Dogmatisch. In H.D. Betz, D. S. Browning, B. Janowski \& E. Jüngel (Hrsg.), Religion in Geschichte und Gegenwart (4. Aufl.; Bd. 5; S. 218-220). Tübingen: Mohr Siebeck.

Rosenau, H. (1996). Schöpfungsordnung. In G. Müller (Hrsg.), Theologische Realenzyklopädie (Bd. 30; S. 356-358). Berlin: De Gruyter.

Scheidegger, J. (2012). Michel Henry - Transzendentale Leiblichkeit. In E. Alloa, T. Bedorf, C. Grüny \& T. N. Klass (Hrsg.), Leiblichkeit (S. 100-115). Tübingen: MohrSiebeck.

Scheuter, S. \& Oldenhage, T. (2008). Mutterbilder zwischen Erfahrung und Konstruktion. In H. Walz \& D. Plüss (Hrsg.), Theologie und Geschlecht. Dialoge querbeet (S. 71-74). Wien: Lit-Verlag.

Schmitz, S. (2009). Wie kommt Geschlecht ins Gehirn? Über den Geschlechterdeterminismus in der Hirnforschung und Ansätze zu seiner Dekonstruktion In M. Bidwell-Steiner \& M.K. Wiedlack (Hrsg.), Gender, Science and Technology (S. 9-16). Wien: Referat Genderforschung der Universität Wien.

Schochow, M. (2010). In den Leib geschnitten. Produktionsformen des biologischen Geschlechts. Geschlecht - Wissen - Geschichte. Österreichische Zeitschrift für Geschichtswissenschaften, 21(1), 10-36. 
Schrey, H.-H. (1990). Leib/Leiblichkeit. In G. Müller (Hrsg.), Theologische Realenzyklopädie (Bd. 20; S. 638-643). Berlin: De Gruyter.

Schüle, A. (2005). Made in the »Image of God«. The Concepts of Divine Images in Gen 1-3. Zeitschrift für Alttestamentliche Wissenschaft (ZAW), 117(1), 1-20.

Schürmann, V. (2012). Max Scheler und Helmuth Plessner - Leiblichkeit in der Philosophischen Anthropologie. In E. Alloa, T. Bedorf, C. Grüny \& T.N. Klass (Hrsg.), Leiblichkeit (S. 207-223). Tübingen: Mohr-Siebeck.

Schurz, G. (2011). Einführung in die Wissenschaftstheorie (3. Aufl.). Darmstadt: Wissenschaftliche Buchgesellschaft.

Schwöbel, C. (2002). Gott in Beziehung. Studien zur Dogmatik. Tübingen: Mohr Siebeck.

Schwöbel, C. (2012). The Religion of Nature and the Nature of Religion. In D. Evers, M. Fuller, A. Jackelén \& T. A. Smedes (Hrsg.), Is Religion Natural? (Issues in Science and Theology) (S. 147-170). London und New York: T\&T Clark International.

Spiekermann, H. (2000). Ambivalenzen. Ermöglichte und verwirklichte Schöpfung in Genesis 2f. In A. Graupner, H. Delkurt \& A. B. Ernst (Hrsg.), Verbindungslinien (FS für Werner H. Schmidt) (S. 363-376). Neukirchen-Vluyn: Neukirchner Verlag.

Standhartinger, A. (2008). »Göttliche Menschwerdung ... in einem männlichen Körper?« In H. Walz \& D. Plüss (Hrsg.), Theologie und Geschlecht. Dialoge querbeet (S. 71-74). Wien: Lit-Verlag.

Tillich, P. (1956). Systematische Theologie. Band I (3., vom Verf. überarb. Aufl.). Stuttgart: Evangelisches Verlagswerk. (Engl. Orig. [1951-1963]. Systematic Theology).

Tillich, P. (1958). Systematische Theologie. Band II (2. Aufl.). Stuttgart: Evangelisches Verlagswerk.

Tillich, P. (1984). Systematische Theologie. Band III (4. Aufl.). Stuttgart: Evangelisches Verlagswerk.

Vatikanische Glaubenskongregation (2004). Schreiben an die Bischöfe der katholischen Kirche über die Zusammenarbeit von Mann und Frau in der Kirche und in der Welt. Rom.

Voß, H.-J. (2010). Making Sex Revisited. Dekonstruktion des Geschlechts aus biologischmedizinischer Perspektive. Bielefeld: Transcript.

Voß, H.-J. (2011). Geschlecht. Wider die Natürlichkeit. Stuttgart: Schmetterling-Verlag.

Voß, H.-J. (2012). Intersexualität - Intersex. Eine Intervention. Münster: Unrast.

Walz, H. \& Plüss, D. (Hrsg.). (2008). Theologie und Geschlecht. Dialoge querbeet. Wien: Lit-Verlag.

Wiesemann, C. (2010). Ethical guidelines for the clinical management of intersex. Sexual Development, 4(4-5), 300-303.

Wolf, E. (1988). Sozialethik. Theologische Grundfragen. Unter Mitarb. von F. Wolf \& U. A. Wolf. Hrsg. von T. Strohm (3. Aufl.). Göttingen: Vandenhoeck \& Ruprecht.

\section{Intersex-Verbände}

http://www.intersexuelle-menschen.net (Verein Intersexuelle Menschen e.V.)

http://www.zwischengeschlecht.org

http://www.isna.org (Intersex Society of North America) 
Torsten Linke

Sexualität und Familie Möglichkeiten sexueller Bildung im Rahmen erzieherischer Hilfen

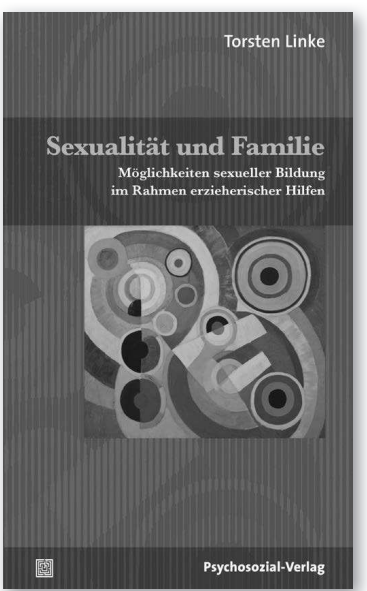

$2015 \cdot 109$ Seiten $\cdot$ Broschur ISBN 978-3-8379-2468-8

\begin{abstract}
Obwohl sexuelle Themen ein wichtiger Bestandteil der sozialpädagogischen Familienberatung und der Kinder- und Jugendhilfe sind, gibt es nur wenige Veröffentlichungen zum Thema.
\end{abstract}

Auch in der konkreten Praxis der Sozialen Arbeit sind theoretische Konzepte für sexuelle Bildung und Beratung ungenügend verankert. Dieser Lücke wendet sich der vorliegende Band zu: Ausgehend von der Studie »Partner 4« zu Jugendsexualität liefert er nicht nur allgemeine Anregungen für die Beratungspraxis, sondern unterbreitet auch Vorschläge für Konzepte, die den diversen und komplexen Lebenslagen der Kinder und Jugendlichen Rechnung tragen. Der Fokus liegt dabei auf der Sozialisationsinstanz Familie. 
Das geschlechtliche Selbsterleben als wesentliches Merkmal menschlicher Identität läuft oftmals der Vorstellung einer bipolaren Geschlechterordnung zuwider. Intersexualität steht quer zu dieser sozialen Geschlechterkonstruktion, die nicht nur in der christlich-theologischen Anthropologie oft als unhinterfragte Leitdifferenz vertreten wird.

Ausgehend von medizinischbiologischen sowie sozialen As- pekten von Intersex wirft Conrad Krannich grundlegende Fragen für die theologische Anthropologie und Ethik auf. Mithilfe klassischtheologischer Denkfiguren legt er den Konstruktionscharakter der geschaffenen Wirklichkeit offen und ermöglicht so ein Verständnis für die Ambivalenz und Mehrdeutigkeit sexueller Identität. Damit ist auch der Weg zu einem angstfreien Umgang mit den Vieldeutigkeiten menschlicher Existenz eröffnet.

Conrad Krannich ist Vikar in der Evangelischen Kirche in Mitteldeutschland. Er studierte evangelische Theologie in Greifswald, Tübingen, Jerusalem und Halle und engagiert sich im interreligiösen Gespräch. Er ist Mitbegründer der nach dem Amoklauf in Winnenden ins Leben gerufenen Initiative "Keine Mordwaffen als Sportwaffen! «.

\section{www.psychosozialivingiag.de}

